\title{
Periodismo de investigación política en nuevos medios: Lista Falciani, Tarjetas Black y Caso Tarajal
}

\author{
MHCJ no 6 | Año 2015 \\ Artículo $\mathrm{n}-5$ (66) \\ Páginas 91 a 128 \\ mhjournal.org
}

Lis Gaibar García | lisgaibar@gmail.com
Universidad Miguel Hernández de Elche
Palabras clave

Periodismo de investigación; fiscalización del poder; nuevos medios; acción ciudadana; periodismo de datos; Lista Falciani; Tarjetas Black; Caso Tarajal; eldiario.es; El Confidencial

\section{Sumario}

1. Introducción. 1.1. Justificación. 1.2. Objeto de estudio. 1.3. Objetivos. 1.4. Hipótesis. 1.5. Método.

2. Marco teórico.

3. Resultados. 3.1. Las nuevas tecnologías y la pérdida de credibilidad en los medios.

3.2. El cambio político y la independencia de los medios. 3.3. Corrupción, periodismo de datos y Ley de Transparencia. 3.4. Características del periodismo de investigación en los casos analizados. 3.5. Cambios en el paradigma mediático que propician la fiscalización del poder. 3.6. Impacto de los casos analizados.

4. Conclusiones.

5. Bibliografía.

6. Notas.

\section{Resumen}

El avance de las nuevas tecnologías está favoreciendo un cambio en el paradigma mediático. Progresivamente, los medios de comunicación apuestan por nuevas técnicas y perfiles profesionales que respondan a las demandas informativas de la audiencia. Este estudio se centra en el proceso de revitalización del periodismo de investigación que impulsan los nuevos medios de comunicación que, a través del empleo de avanzadas herramientas y complejas metodologías, favorecen la publicación de informaciones referentes a la corrupción o a los abusos del poder en España. Estas publicaciones son posibles, en gran parte, gracias a la independencia de estos nuevos medios con respecto a los poderes políticos y económicos.

El objetivo de la presente investigación consiste en comprobar, mediante el análisis cualitativo y cuantitativo, si existen evidencias significativas que demuestren que los nuevos medios de comunicación, nativos digitales, están recuperando la función del periodismo como fiscalizador del poder. Para ello, la investigación parte del análisis de tres de los casos de corrupción y abusos del poder más sonados en España en los últimos dos años: las Tarjetas Black de Caja Madrid, la Lista Falciani y el Caso Tarajal. Los tres casos estudiados fueron publicados en exclusiva, o investigados en profundidad, por los dos medios nativos digitales más consumidos en España según el informe 'Digital News Reports 2015’ de Reuters: eldiario.es y El Confidencial.

Forma de citar este artículo en las bibliografías

Lis Gaibar García (2015): "Periodismo de investigación política en nuevos medios: Lista Falciani, Tarjetas Black y Caso Tarajal", en Miguel Hernández Communication Journal, nº, páginas 91 a 128. Universidad Miguel Hernández, UMH (Elche-Alicante). Recuperado el de de 20__ de: Џink del artículo en mhjournal.org] 


\title{
Political investigative journalism in new mass media: SwissLeaks, Black Credit Cards and Tarajal Case
}

MHCJ no 6 | Year 2015

Lis Gaibar García | lisgaibar@gmail.com

Paper no 5 (66)

Pages 91 to 128

mhjournal.org

\author{
Universidad Miguel Hernández de Elche
}

Keywords

Investigative journalism; authority audit; new mass media; civic action; data journalism; SwissLeaks; black credit cards; Tarajal Case; El Confidencial; eldiario.es

\section{Sumary}

1. Introduction. 1.1. Justification. 1.2. Object of study. 1.3. Objectives. 1.4. Hypothesis. 1.5. Method.

2. Theoretical framework.

3. Results. 3.1. New technologies and the loss of credibility in the mass media. 3.2. Political change and independence of the mass media. 3.3. Corruption, data journalism and Transparency Act. 3.4. Features of investigative journalism in the analyzed cases. 3.5. Changes in the media paradigm conducive to the control of power. 3.6. Impact of the analyzed cases.

4. Conclusions and proposals.

5. Bibliography.

6. Notes

\section{Abstract}

The advance of new technologies is favoring a change in the media paradigm. To an increasing extent, the media are betting on new technical and professional profiles that respond to information requests from the audience. Our study focuses on the revitalization of investigative journalism being produced from the new mass media, through the use of advanced tools and complex methodologies, promoting the publication of information relating to corruption or abuse of power in Spain. These publications are possible greatly due to the independence of these new mass media regarding the political and economic powers.

The objective of this research is to verify by qualitative and quantitative analysis, if there is any significant evidence to show that the new mass media, digital natives, are recovering the function of journalism as a watchdog of democracy. In order to prove this, the research focuses the attention on the analysis of three cases of corruption and abuse of power in Spain most popular in the last two years: the 'black' cards of Caja Madrid, Swiss Leaks and Tarajal Case. The three case studies were published exclusively, or minutely investigated, by the two digital native mass media most consumed in Spain according to the report '2015 Digital News Reports' of Reuters: eldiario.es and El Confidencial.

\section{How to cite this paper in bibliographies}

Lis Gaibar García (2015): "Political investigative journalism in new mass media: SwissLeaks, Black Credit Cards and Tarajal Case”, en Miguel Hernández Communication Journal, nº, pages 91 to 128. Universidad Miguel Hernández, UMH (Elche-Alicante). Recuperado el de de 20__ de: @ink del artículo en mhjournal.org] 


\section{Introducción}

En los últimos años se ha incrementado el número de informaciones relacionadas con casos de corrupción política o de abusos del poder. El periodismo de investigación política en España experimenta un perceptible auge; y si bien algunos medios de comunicación tradicionales realizan una buena labor de investigación, se hace evidente que los medios nativos digitales, independientes de los poderes políticos y del amparo de las grandes empresas, poseen mayor libertad para hacer públicas informaciones incómodas para las altas esferas de la política y la economía. Medios nativos digitales, tales como eldiarioes y El Confidencial, contribuyen al retorno del periodismo como 'Cuarto poder' y centran sus esfuerzos en recuperar su función de 'perro guardián' o watchdog de la democraciaํ․

Uno de los casos de periodismo de investigación política más sonados en España en los últimos años ha sido el de las Tarjetas Black; un delito de corrupción que configura un buen ejemplo de la función del periodismo como cuarto poder: la investigación de las tarjetas se inició a raíz de la publicación de los correos de Blesa por el eldiario.es. La manera en que eldiario.es accedió a esa información también es un claro ejemplo del cambio que se está produciendo en el ecosistema mediático: el medio recibió los correos de Blesa a través de una fuente anónima derivada por el Partido $\mathrm{X}^{2}$.

También las nuevas tecnologías influyen en el auge del periodismo de investigación al proporcionar al periodista herramientas y tecnologías que facilitan su trabajo, como es el caso del periodismo de datos.

El análisis de datos fue la disciplina para desarrollar el segundo caso de estudio de la presente investigación: la Lista Falciani, una relación de personas, familias y empresas que tenían y tienen depósitos y cuentas en la sucursal suiza del banco HSBC.

También se configura como objeto de estudio el grado de accesibilidad a informaciones oficiales en España y la efectividad de la Ley de Transparencia puesta en marcha en diciembre de 2014. En este sentido, la fundación ciudadana Civio, que ocupa el primer puesto en el Ranking de Innovación Periodística realizado por el Máster de Innovación en Periodismo (MIP) de la Universidad Miguel Hernández, insiste en la necesidad de "simplificar el acceso a la información" y "reglamentar de manera correcta la ley para reducir la arbitrariedad".

Si bien los últimos casos de corrupción han suscitado el interés de la opinión pública, no es este tipo de periodismo de investigación político el único que nos ocupa. El periodismo social también es fiscalizador, y por ello el tercer caso de estudio se fundamenta en el especial multimedia de 'Las muertes de Ceuta', elaborado por eldiario.es con motivo del aniversario de la tragedia de Ceuta, en la que 15 personas murieron cuando intentaban entrar a España.

Utilizando fundamentalmente la metodología cualitativa, el estudio pretende determinar si los medios nativos digitales están recuperando la función del periodismo como cuarto poder o 'perro guardián de la democracia'. Del mismo modo, pretendemos demostrar que la independencia de los medios de comunicación es un factor clave para desempeñar esta tarea; independencia que la mayoría de medios tradicionales no posee al estar ligados a intereses políticos o empresarios por motivos de rentabilidad del propio medio. 


\subsection{Justificación}

Esta investigación parte de la detección de un cambio en el ecosistema mediático y de una necesidad creciente, tanto por parte de ciudadanos como por parte de periodistas, de conocer la realidad política de nuestro país y colaborar en la construcción de un sistema democrático más justo que vele por los intereses de los ciudadanos.

En los últimos años se ha incrementado el número de publicaciones referentes a casos de corrupción. Si bien no son exclusividad de los medios nativos digitales, el fenómeno sí que coincide con el auge de las nuevas tecnologías de la información y el uso de programas informáticos, que favorecen el análisis de cantidades ingentes de información.

También será objeto de estudio la nueva 'Ley de Transparencia, acceso a la información pública y buen gobierno', que entró en vigor el 10 de diciembre de 2014. Y si bien las fuentes oficiales resultan una fuente fundamental para los periodistas, la creación de plataformas que permiten la filtración de documentos o informaciones de manera completamente anónima reflejan un deseo por parte de la ciudadanía a participar en los asuntos políticos y construir una sociedad más justa.

\subsection{Objeto de estudio}

Nuestra investigación se centra en el análisis de tres casos concretos, publicados entre 2014 y 2015 en dos medios nativos digitales, de información generalista y de alcance nacional: eldiario.es y El Confidencial.

1. Análisis del caso de 'Las Tarjetas Black', una serie de tarjetas "opacas a efectos fiscales" que fueron utilizadas por consejeros y directivos de Caja Madrid. Las informaciones fueron publicadas en exclusiva por eldiario.es tras una investigación iniciada a raíz de las filtraciones de los correos de Blesa por parte de una fuente anónima derivada del Partido X.

2. Análisis del caso 'Lista Falicani' o 'SwissLeaks', una lista facilitada a los medios que fue filtrada por el informático Hervé Falciani, entonces empleado de la rama suiza del banco británico HSBC. En ella han trabajado más de 140 periodistas de 45 países distintos y han participado más de 60 medios de comunicación; en España fueron El Confidencial y La Sexta.

3. Análisis del caso 'Las muertes de Ceuta', un proyecto de eldiario.es en el que el medio desmontó la versión oficial a través de la reconstrucción de los hechos acontecidos el 6 de febrero de 2014, cuando 15 personas perdieron la vida intentando acceder a España. Eldiario.es llevó a cabo un trabajo de investigación a partir de los testimonios de los protagonistas y las grabaciones en el lugar de los hechos, facilitadas por fuentes oficiales.

\subsection{Objetivos}

Los objetivos de la presente investigación consisten en analizar los fenómenos sociales y políticos detectados a raíz de publicaciones recientes que, mediante exhaustivas investigaciones, han contribuido a informar a la ciudadanía de los abusos del poder. Para ello, construimos determinadas hipótesis que serán confirmadas o desmentidas a través del análisis cuantitativo y cualitativo de estos objetos de estudio: 
1. Optimización del periodismo de investigación, a través del empleo de nuevas tecnologías y del trabajo en equipo (multidisciplinario o no) de profesionales, que permite llevar a cabo grandes investigaciones.

2. Incremento de los casos de periodismo como fiscalizador del poder, lo cual desemboca a su vez en un incremento de la pluralidad informativa.

3. Mayor participación del público en los procesos comunicativos, tanto en la preproducción de la información (a través de filtraciones que inician las investigaciones) como en la postproducción, mediante el feedback con los medios de comunicación.

El estudio pretende analizar el cambio en el ecosistema mediático, centrando la atención en el papel de los medios nativos digitales. Por ello, en las líneas que sigue se profundiza en la relación entre las recientes publicaciones que sirven como denuncia de los abusos del poder y la viabilidad económica de los medios que han difundido dichas informaciones.

\subsection{Hipótesis}

Como hemos indicado en anteriores apartados, a través de la metodología empleada, se pretende demostrar si se cumplen las siguientes hipótesis:

H1: Los medios nativos digitales están recuperando la función del periodismo como cuarto poder o "perro guardián de la Democracia'; esto es, los nuevos medios fiscalizan al poder politico

Definición de términos: Consideramos que en los últimos años, los nuevos medios de comunicación (en su mayoría nativos digitales) están ejerciendo un papel fiscalizador. El periodismo de investigación que se realiza desde las redacciones sirve de control a las instituciones y a los partidos políticos.

Técnica de análisis: Análisis de contenido.

H2: Elperiodismo de investigación, a través del análisis de datos y del empleo de nuevas tecnologías y de nuevas narrativas, está ganando prestigio en España.

Definición de términos: Pese a que muchos medios tradicionales atraviesan dificultades económicas, algunos de ellos apuestan por perfiles profesionales innovadores e invierten parte de sus ingresos en nuevas tecnologías. Ambos factores favorecen el desarrollo de investigaciones que son presentadas de manera comprensible para la audiencia, lo cual incrementa el impacto de dichas investigaciones y, por ende, el prestigio del medio de comunicación. Este tipo de periodismo está cobrando relevancia en España de manera paulatina, configurándose como ejemplo de periodismo de calidad y servicio público.

Técnica de análisis: Análisis de contenido

H3: La independencia económica y politica de los medios nativos digitales favorece la publicación de informaciones incómodas para el poder politico y económico.

Definición de términos: Los modelos de negocio de medios nativos digitales, que posibilitan su independencia con respecto a los partidos políticos y las instituciones, permiten al periodista publicar determinadas informaciones contrarias a intereses económicos y políticos de dichos poderes públicos. 
Técnica de análisis: Análisis de contenido.

H4: Los medios tradicionales están limitados en la difusión de determinadas informaciones publicadas por los nativos digitales, pese a que éstas resulten de gran interés para la ciudadanía.

Definición de términos: El estudio pretende demostrar que el fenómeno anteriormente descrito sucede a la inversa; la posesión o la participación accionarial en diversos medios de comunicación por parte de las élites gobernantes o influyentes impiden al profesional de la información actuar con total libertad en lo que a contenido informativo se refiere. Esto impide que el periodismo cumpla su función de servicio público.

Técnica de análisis: Análisis de contenido, análisis cuantitativo.

H5: La participación ciudadana y la creación de herramientas de filtración de informaciones van en aumento y posibilitan que salgan a la luz casos de corrupción política.

Definición de términos: El estudio pretende demostrar que en los últimos años se está produciendo un incremento de la participación ciudadana, traducida en el ámbito político como movimientos y grupos organizados y en el mediático como fuentes y no sólo como audiencia. El ciudadano participa activamente en el proceso comunicativo; no sólo a través del feedback con los medios, sino incluso realizando filtraciones para que éstos inicien las investigaciones pertinentes.

Técnica de análisis: Análisis de contenido, análisis cuantitativo

H6: La nueva Ley de Transparencia y los contenidos a los que se puede acceder a través de ésta están siendo aprovechados por los profesionales de la información para denunciar casos de corrupción o abusos del poder.

Definición de términos: Se pretende conocer si la aprobación de la Ley 19/2013, de 9 de diciembre, de transparencia, acceso a la información y buen gobierno, está siendo utilizada por los profesionales de información para obtener datos de las instituciones públicas de interés para la ciudadanía.

Técnica de análisis: Análisis de contenido.

\subsection{Metodología}

\subsubsection{Metodología cuantitativa}

Una manera de determinar el impacto de las tres informaciones analizadas es estudiar el número noticias publicadas referentes a los casos, tanto en medios nativos digitales como en las ediciones digitales de medios tradicionales.

Para ello se realiza una consulta de la hemeroteca de los medios digitales de comunicación más visitados de España, así como los que configuran el objeto de estudio: El País, El Mundo, ABC y La Razón; Eldiario.es y El Confidencial. Se tendrán en cuenta las publicaciones de tipo informativo, interpretativo y opinativo con el fin de profundizar en la cobertura de los casos. 
Para determinar de manera más concreta esta cobertura, se establece un periodo de tiempo determinado para cada una de ellas, correspondiente a la fecha de publicación de cada escándalo:

- Lista Falciani: se analiza el periodo comprendido entre el 1 de febrero de 2015 y el 28 de febrero de 2015. Para ello se consulta las informaciones etiquetadas como "Lista Falcianil", "Swiss Leaks" o ambas.

- Tarjetas Black: se analiza el periodo comprendido entre el 1 de octubre de 2014 y el 31 de octubre de 2014. Se consultan las informaciones con las etiquetas "Tarjetas Black", "Tarjetas B" y "Caja Madrid".

- Caso Tarajal: Se analizan las informaciones publicadas entre el periodo comprendido el 6 de febrero de 2015 y el 30 de abril de 2015. Los criterios de búsqueda empleados son "Caso Tarajal", "Muertes de Ceuta", o "guardias civiles".

La elección de fechas no es casual: El 8 de febrero de 2015, El Confidencial anunció que iría descubriendo los nombres de la Lista Falciani “en los próximos días". A partir del 9 de febrero, el digital amplió progresivamente información de dicha filtración y los medios de comunicación se hicieron eco de la noticia.

Por otra parte, para establecer el inicio de la publicación de informaciones referidas a las tarjetas 'black' de Caja Madrid, tendríamos que remontarnos a diciembre de 2013, cuando eldiario.es publicó una noticia titulada "Los consejeros de Caja Madrid tenían tarjetas de crédito 'en negro' de hasta 50.000 euros al año". Sin embargo, fue el día 2 de octubre de 2014 cuando se hizo pública la lista de consejeros de Caja Madrid que habían hecho uso de las tarjetas "opacas", emitidas al margen del circuito general. No obstante, este escándalo de corrupción se ha mantenido en la agenda setting de los medios desde entonces: son muchas las informaciones que se han publicado, desde octubre de 2014 hasta junio de 2015, sobre dimisiones, destituciones, ceses o investigaciones derivadas del uso de las tarjetas 'black'.

Con respecto al Caso Tarajal, se elige para el estudio cuantitativo el periodo comprendido entre el 6 de febrero de 2015 al 30 de abril del mismo año. El 6 de febrero se conmemoraba el primer aniversario de la muerte de los 15 inmigrantes que perdieron la vida al intentar acceder a España; desde entonces, se abrieron procesos judiciales para investigar la responsabilidad de la Guardia Civil española en la tragedia. Con el fin de hacer un seguimiento de dicho proceso jurídico, se establece un rango temporal más amplio que en los otros dos casos.

Otra herramienta empleada como parte de la metodología cuantitativa consiste en los resultados de las encuestas de elaboración propia que pretenden profundizar en el nivel de conocimiento de los tres casos analizados y en los hábitos de consumo de información política entre los españoles. Las encuestas han sido realizadas personalmente y la muestra comprende un total de 120 personas de todas las edades que presentan diferencias tanto en el nivel de estudios como en la ocupación, diversidad que pretende rigor en la investigación científica.

La encuesta consta de nueve preguntas destinadas a conocer el impacto de los tres casos analizados, los medios de comunicación más consultados en España y la valoración de los medios nativos digitales en lo que a periodismo político se refiere.

Una tercera parte de la metodología ha sido el análisis del impacto de estas informaciones, no sólo en los medios de comunicación y en la ciudadanía, sino también en los propios organismos o instituciones involucradas en los casos. Para profundizar en el impacto de estas informaciones, elaboramos una tabla en la que se detallarán los nombres y los cargos de 
aquellos que fueron expulsados, destituidos o que dimitieron tras el escándalo de las tarjetas 'black'. De igual manera, se profundiza en las consecuencias de la publicación de la Lista Falciani y en el de las muertes de Ceuta, si bien estos dos últimos casos se analizan de manera cualitativa.

\subsubsection{Metodología cualitativa}

El trabajo se fundamenta en las declaraciones obtenidas de profesionales de la información que han participado en los casos analizados.

- Mar Cabra, periodista especializada en datos, miembro del ICIJ (Consorcio Internacional de Periodistas de Investigación, una red global de periodistas de investigación que trabajan de manera colaborativa) e investigadora en el caso de la Lista Falciani. La entrevista se realizó vía telefónica el viernes 15 de mayo de 2015;

- Daniele Grasso, periodista de la unidad de datos de El Confidencial que también participó en las investigaciones de la Lista Falciani. La entrevista se realizó de manera personal el martes 24 de marzo de 2015;

- Antonio Delgado, periodista especializado en datos que colabora con eldiario.es y elaboró informaciones referentes a las Tarjetas Black. La entrevista se realizó de manera personal el viernes 24 de abril de 2015;

- Alejandro Navarro, licenciado en Comunicación Audiovisual, trabajador en eldiario.es y miembro del equipo del especial 'Las muertes de Ceuta'. La entrevista se realizó de manera personal el jueves 23 de abril de 2015.

Otra fuente de información han sido las conferencias o seminarios a los que se ha asistido de manera presencial o se han seguido vía telemática:

- X Jornadas Internacionales de Periodismo (Elche, 24 y 25 de marzo de 2015, presencial): se utiliza material de las ponencia de Juan Luis Sánchez, subdirector de eldiario.es y coordinador de 'Las muertes de Ceuta'; de Ana Pastor, periodista de El Objetivo de La Sexta; de Eva Belmonte, periodista de fundación ciudadana Civio; de Eva Domínguez, experta en periodismo digital; y de Daniele Grasso, periodista de datos de El Confidencial.

- III Jornadas de Periodismo de Datos (Madrid, del 4 al 7 de mayo de 2015, streaming y seguimiento en Twitter): Se emplea material de las ponencias de Al Shaw, de la plataforma ProPublica; de Jesús Escudero, periodista de datos en El Confidencial; y de los ya mencionados Mar Cabra; Daniele Grasso y Antonio Delgado.

- Jornada de Periodismo de Investigación (Granada, 25 de abril, seguimiento por twitter): se extraen declaraciones de la ponencia de Marcos García Rey, periodista especializado en datos, investigador de la Lista Falciani y único miembro español del ICIJ junto a Mar Cabra.

- Jornadas Open E2 Arena (Elche, 15 de mayo de 2015, presencial): Se emplea material de la conferencia sobre Big Data impartida por J.J. Melero.

- Jornadas de Empleo de Periodismo: Se utilizan las declaraciones de Alejandro Navarro, licenciado en Comunicación audiovisual y encargado de la producción audiovisual del especial 'Las muertes de Ceuta'.

- Seminarios de la asignatura 'Comunicación política' (Elche, varias fechas, presencial): Para ampliar la fundamentación del estudio, se utilizan declaraciones extraídas a partir 
de la asistencia a seminarios de la asignatura 'Comunicación política y opinión pública', en especial de Juan Luis Sánchez, subdirector de eldiario.es.

También se estudian los cuadernos eldiario.es, una colección de monográficos que dicho medio publica trimestralmente. Los utilizados han sido: Cuaderno 4 ('Retrato del poder', sobre los correos de Blesa que iniciaron las investigaciones de las tarjetas 'black'), Cuaderno 7 ('La caja B de la democracia', que profundiza en los paraísos fiscales y en la Lista Falciani) y Cuaderno 8 ('Fronteras y mentiras', centrada en la inmigración y que forma parte del especial 'Las muertes de Ceuta').

Los informes se configuran como otra fuente de conocimiento: entre ellos, el Informe Anual de la Profesión Periodística 2015 elaborado por la APM; o el de Reuters sobre hábitos de consumo de información digital: Digital News Report 2015. La bibliografía de otros autores y la lectura numerosos artículos y noticias sobre los casos tratados configura otra fuente de conocimiento para la realización de este estudio.

\section{Marco teórico}

La democracia representativa presenta tres principios organizadores fundamentales (Norris, 2000): la posibilidad de competencia entre opciones políticas; la participación activa de los ciudadanos en la elección entre esas opciones; y el reconocimiento y protección de determinadas libertades que garanticen ambos derechos (el pluralismo político y la participación ciudadana). A estos principios, Martínez Nicolás (2011) suma "la exigencia ética de que los procesos políticos (formación de decisiones legítimas y vinculantes para toda la comunidad) se conduzcan en condiciones de publicidad, a la luz pública".

Los medios de comunicación son el cauce más efectivo que posee el ciudadano para entender e involucrarse en las cuestiones políticas, y cumplir así el fin último del modelo democrático: la participación ciudadana. Tanto la política como el periodismo se constituyen como instituciones sociales imprescindibles en una democracia, pues poseen una fuerte conexión con el correcto funcionamiento de ésta. El profesor Andreu Casero-Ripollés (2012) explica que existe una interdependencia entre la política y el periodismo y que la interacción que se produce entre ellas da forma a la esfera pública en las sociedades actuales.

La naturaleza política del periodismo hunde sus raíces en el concepto mismo de la profesión periodística (Dader, 2012), que surge con un triple cometido: el seguimiento vigilante de la vida pública; el servicio a los ciudadanos para proporcionarles información sobre sus intereses comunes, los problemas del colectivo y las opciones para resolverlos; y facilitar plataformas de discusión sobre los asuntos que afecten a la sociedad en su conjunto. El periodismo posee una función vertebradora que permite expresar y mantener el vínculo que interrelaciona a los ciudadanos en la comunidad social y política (Dader, 2012). Es ahí donde entran en juego los profesionales de la comunicación, que son los encargados de construir no sólo este capital social sino también la realidad política.

La realidad de los medios de comunicación en España como agentes favorecedores de la participación ciudadana ha sido motivo de estudio en diversas ocasiones. Hallin y Mancini (2008) establecieron tres modelos de relación entre los medios de comunicación y la política e incluyeron a España en el "modelo pluralista polarizado", que se caracteriza por "una 
integración de los medios de comunicación en la política de partidos, un papel activo del Estado en el sistema mediático, un desarrollo histórico relativamente débil de los medios de comunicación comerciales y un nivel de profesionalización menor del periodismo (...) y también por la existencia de una prensa orientada hacia una élite dirigente con tiradas relativamente cortas". De la misma manera, estos dos teóricos explican que existe un alto grado de vinculación o de "paralelismo político" en el modelo pluralista de los medios de comunicación: a nivel teórico se presume de una "concepción liberal" de los medios de comunicación, pero en la práctica "prevalece una concepción instrumental de los mismos, entendidos (...) como mecanismo de influencia política o de promoción comercial". En este mismo estudio, Hallin y Mancini definieron el sistema comunicativo español como "bastante homogéneo y muy centralizado".

La dependencia de los medios de comunicación de las instituciones por cuestiones económicas limita la libertad en los contenidos que se publican en la mayoría de los diarios: la mercantilización de los medios es otro elemento que incide en la relación entre el periodismo y la política (Mosco, 2009) ya que los intereses empresariales y financieros determinan el comportamiento de los medios.

Esta dependencia impide que el periodismo desarrolle con total libertad las cuatro grandes funciones normativas de dicha profesión en el ámbito democrático (McNair, 2009): el deber de mantener a la ciudadanía informada (mediante el periodismo político) para sustentar la democracia; ejercer "una tarea de escrutinio crítico sobre las élites políticas y económicas de la sociedad" (principal objeto de estudio en este trabajo) y alertar de los posibles abusos de éstas; funcionar como mediador entre la ciudadanía y los actores políticos; y ser abogado de determinadas causas, favorables a los principios de la sociedad democrática.

Precisamente con respecto a esta última función, entra en juego el pluralismo político, principio fundamental de la democracia según la Constitución Española (1978) ${ }^{3}$. La línea editorial de los medios es aceptable al configurarse en su mayoría como empresas privadas, y la parcialidad de los profesionales es justificable siempre que se distingan hechos de opiniones. La voluntad de influir en la formación de la opinión pública y persuadir a los ciudadanos conlleva la politización del periodismo e incluso la aparición de "actitudes partidistas" en los medios.

\section{Periodismo de investigación y periodismo de datos}

La revitalización del periodismo de investigación por parte de los medios que apuestan por la elaboración de contenidos propios es posible, en muchos casos, gracias a la colaboración ciudadana; pero también gracias a los nuevos perfiles profesionales.

El periodismo de datos es una disciplina que se enmarca en periodismo de investigación. A nivel nacional, se trata de una especialización que actualmente está en auge y que es posible gracias al avance de las nuevas tecnologías. Existen grandes investigaciones que, según explica el periodista especializado en datos Antonio Delgado, hace unos años no habrían sido posibles al carecer de los medios necesarios. Es el caso de grandes investigaciones como la Lista Falciani.

No obstante, la profesora Karma Peiró explica que el periodismo de datos "no es algo nuevo"; lo que sí que resulta novedoso, dice, "es la manera en la que estamos trabajando los datos 
desde el periodismo". De hecho, el precedente del periodismo de datos es el periodismo de precisión; lo novedoso es el rastreo de bases de datos o database jorunalism, basado en el interés por las cuantificaciones pero también por el sentido del control de la actividad pública (García y Gómez Fernández, 1993).

Precisamente en relación con este control de la actividad pública, cabe destacar que el periodismo de datos deriva, a la vez, de la consolidación del periodismo de investigación. El New Journalism o 'Nuevo Periodismo' se implantó en Estados Unidos en los años 60. Jesús Flores y Cecilia Salinas (2013) explican que a partir de la Revolución de Mayo de 1968 "los periodistas no se conforman con las versiones oficiales, se vuelven desafiantes y escépticos frente al poder y se convierten en valedores de los intereses ciudadanos"; claro ejemplo de ello fue la publicación del caso Watergate.

Cabe destacar en este punto la aportación de Robert Boynton en su obra The New New Journalism (2005), en la que se recogen conversaciones con nuevos profesionales que continúan y actualizan el legado de los 'nuevos periodistas' de la década de los 70. Boynton explicaba en el XXI Congreso de la Sociedad Española de Periodistas (SEP), que esta generación de 'nuevos nuevos periodistas' experimenta, sobre todo, en la manera en la que se consigue la historia; para ello desarrollan estrategias innovadoras de inmersión y dedican más tiempo a la construcción de los hechos. En su obra, traducida recientemente por la Universidad de Barcelona (UB), Boynton apunta que, en detrimento de las técnicas empleadas por los 'nuevos periodistas' de los años 70, las innovaciones de los 'nuevos nuevos periodistas' se centran más en la manera de contar la historia que en el lenguaje empleado para hacerlo.

Antonio Delgado afirma que, en la actualidad, en muchas ocasiones el periodismo de investigación "está basado en fuentes abiertas" ya que "es en Internet donde tenemos la mayor cantidad de información disponible". De esta forma, se hace imprescindible el manejo de tecnologías, técnicas y metodologías que permitan encontrar exclusivas periodísticas.

Una de las fuentes que los profesionales utilizan para el periodismo de investigación son las filtraciones. Los escándalos derivados de la publicación de los gastos de las Tarjetas Black y la Lista fueron posible gracias al auge de dos nuevas figuras:

- La figura del whistleblower o denunciante: se trata de una fuente informativa que filtra información confidencial a una entidad periodística (Albert Castaño, 2014). En los casos estudiados, Hervé Falciani sería un claro ejemplo de whistleblower. H. Burgh (2008) profundiza en el concepto.

"[El whistleblower es] una de las fuentes más importantes de las grandes investigaciones (...) $[\mathrm{y}]$ a diferencia de las fuentes que pueden tener conexiones personales o familiares con la historia, los whistleblowers suelen ser empleados o integrantes (...) dispuestos a arriesgar su sus posiciones profesionales y personales para exponer públicamente el comportamiento criminal o inmoral de sus superiores".

- Las plataformas de denuncia ciudadana: Son portales desde los que cualquier ciudadano puede enviar información, de manera completamente anónima (ni siquiera los receptores conocen el origen de la información) y segura (funcionan por sistemas de código abierto), sobre casos de corrupción, abusos, infracciones o delitos de cualquier índole por parte de individuos e instituciones. Es el caso de filtra.la, la 
plataforma española e independiente en la que colaboran eldiario.es, La Marea, Mongolia, Diagonal y el Partido X. Otro ejemplo de este tipo de plataformas es el buzón del Partido X, a través del cual fueron recibidos los correos de Blesa; o el Buzón de denuncias del reciente nativo digital El Español.

En ambos casos, la filtración sólo constituye el primer paso de la investigación: la fuente informativa siempre tiene un interés, si bien este interés puede ser compartir informaciones que se conviertan (Marta Sánchez, 2015) en "escándalos (...) que busquen generar concienciación social ante un tema de interés público y que ciertas personas o instituciones querrían ocultar".

Aunque el periodismo de datos, tal y como lo conocemos, goza de gran prestigio en Estados Unidos desde mediados de los años 90, en España no comenzó a desarrollarse hasta el año 2011, cuando un grupo de periodistas y personas sensibles con el tema de datos se unieron para fomentar la formación y la utilización de dicha disciplina en las redacciones. Lo hicieron a través de MediaLab Prado, un centro cultural que se define como "laboratorio ciudadano de producción, investigación y difusión de proyectos culturales que explora las formas de experimentación y aprendizaje colaborativo que han surgido de las redes digitales".

El periodismo de datos favorece la elaboración de contenidos propios y permite la publicación de exclusivas. El tratamiento de datos, sin embargo, no está al alcance de todos los usuarios; sólo de aquellos que tengan un determinado nivel de manejo con algunos programas informáticos. En algunas ocasiones se requiere incluso nociones básicas de programación. Mar Cabra explica que, si el periodista no se puede formar en todos los ámbitos, puede consultar a expertos de esas materias. Por tanto, el periodismo de datos favorece la formación del profesional en nuevas tecnologías y la predisposición para el trabajo en equipo multidisciplinar.

\section{Resultados}

\subsection{Las nuevas tecnologías y la pérdida de credibilidad en los medios}

El consumo de información a través de los medios de comunicación digitales, sea cual sea el soporte, mantiene una tendencia creciente, tal y como lo demuestran diversos estudios sobre consumo de noticias.

Podríamos dividir los medios de comunicación digitales en dos grupos: ediciones digitales de medios tradicionales (ElPaís.com, ElMundo.es, ABC.es...) y medios nativos digitales (eldiario.es, El Confidencial, infoLibre, El Español...). El segundo grupo, cada vez más numeroso, incluye los medios exclusivamente digitales, lo cual no implica que no puedan estar presentes en otros formato4.

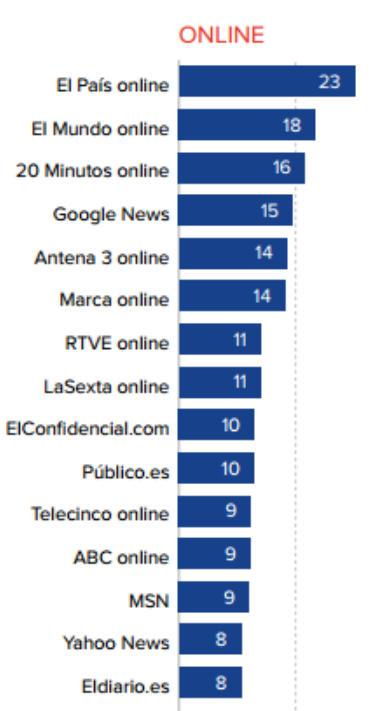

Ilustración 1 - Medios más utilizados por los usuarios para acceder a las noticias / Fuentes: Digital New Reports 
La edad del usuario es un condicionante en el consumo de medios. Por ejemplo, eldiario.es alcanza a un público joven, presentándose como el sexto medio generalista de preferencia para la población de 18 a 24 años.

Las encuestas realizadas confirman que cada vez más ciudadanos se informan de la actualidad política a través de Internet. Más de un $85 \%$ de los entrevistados afirma hacerlo, si bien un $62 \%$ de ellos prefiere otros medios de comunicación como la televisión, la radio o la prensa escrita.

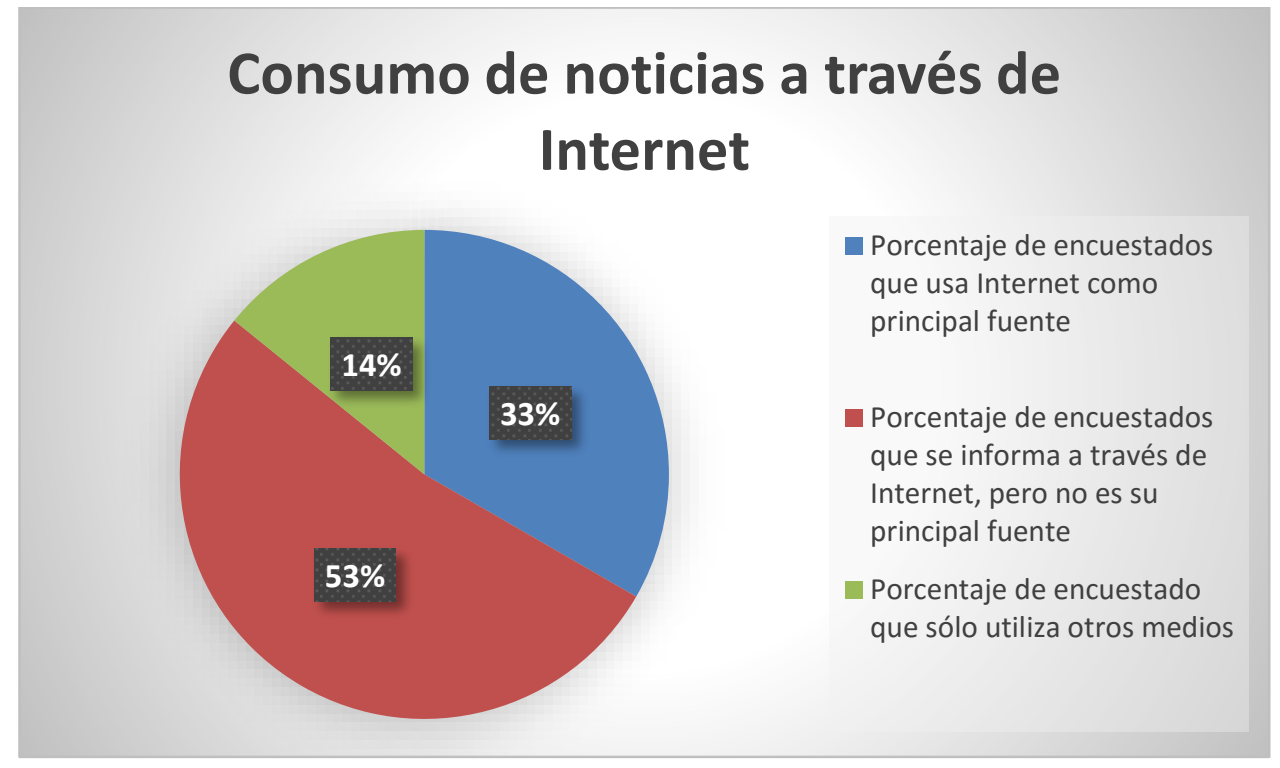

Ilustración 2 - Hábitos de consumo de información de los encuestados / Fuente: Elaboración propia

También se hace evidente que tanto eldiario.es y El Confidencial se configuran como dos de los medios nativos digitales con mayor sobrenombre; un $83 \%$ de los encuestados afirma conocer uno o ambos medios.

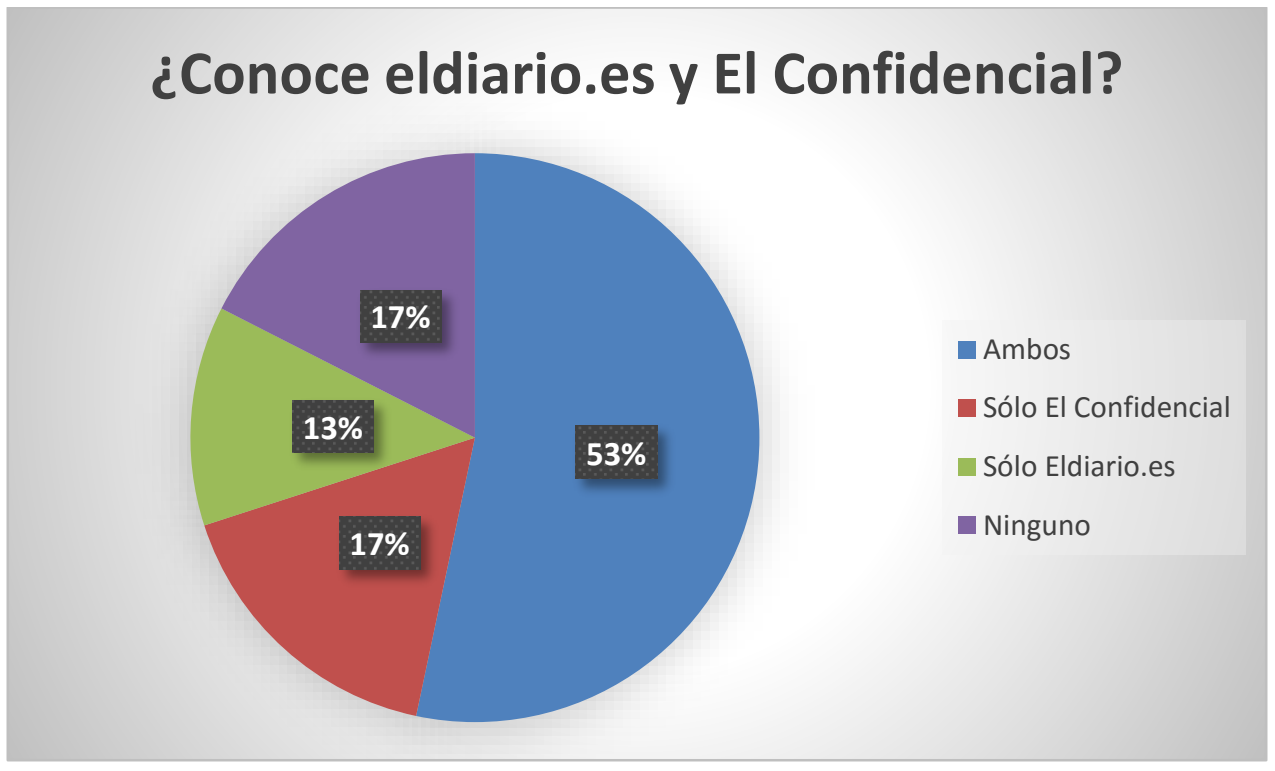

Ilustración 3 - Porcentaje de usuarios que conoce eldiario.es y El Confidencial / Fuente: Elaboración propia 
Pese a ello, los encuestados no se sienten muy informados acerca de la actualidad política en España: en una escala del 0 al 5, siendo 0 nada informado y 5 perfectamente informado, la media de sus respuestas se sitúa en un 2,7 (medianamente informados).

\subsection{El cambio político y la independencia de los medios}

El auge del periodismo político y la preocupación por los temas de interés ciudadano están estrechamente ligados a los cambios políticos que está experimentando España en los últimos tiempos.

El 24 de mayo de 2015, las elecciones municipales y autonómicas evidenciaron una ruptura con el bipartidismo en España. Los nuevos partidos políticos se colocaron a la cabeza en cuanto a número de escaños obtenidos. Durante los días previos a las elecciones municipales y autonómicas, los medios nativos digitales centraron sus esfuerzos en la difusión de noticias relacionadas con la corrupción política de los partidos mayoritarios: eldiario.es lo hizo con los papeles de Naseiro o con el despilfarro de Rita Barberá como alcaldesa de Valencia; infoLibre con la declaración de la renta de Esperanza Aguirre. Los medios tradicionales hicieron lo propio; sin embargo, su línea editorial condicionó de manera notable el número de informaciones publicadas al respecto de los casos de corrupción.

Los resultados del estudio de la cobertura de los casos estudiados por parte de los principales medios digitales bajo las coordenadas indicadas en la metodología indican lo siguiente:

\begin{tabular}{|l|l|l|l|l|l|l|}
\hline & Eldiario.es & $\begin{array}{l}\text { El } \\
\text { Confidencial }\end{array}$ & El País & $\begin{array}{l}\text { El } \\
\text { Mundo }\end{array}$ & ABC & $\begin{array}{l}\text { La } \\
\text { Razón }\end{array}$ \\
\hline $\begin{array}{l}\text { Lista Falciani } \\
\text { (Febrero 2015) }\end{array}$ & 19 & 37 & 25 & 29 & 33 & 19 \\
\hline $\begin{array}{l}\text { Tarjetas Black } \\
\text { (Octubre 2014) }\end{array}$ & 220 & 96 & 109 & 112 & 184 & 19 \\
\hline $\begin{array}{l}\text { Caso Tarajal } \\
\text { (Febrero-Abril } \\
\text { 2015) }\end{array}$ & 9 & 43 & 14 & 14 & 18 & 6 \\
\hline
\end{tabular}

Tabla 1 - Cobertura informativa de los casos estudiados en los principales medios digitales de España I Fuente: Elaboración propia

Resulta pertinente puntualizar determinados aspectos que explican los resultados:

- El número de informaciones publicadas en eldiario.es sobre el Caso Tarajal puede parecer escaso, pero cabe destacar la elaboración del especial 'Las muertes de Ceuta' por parte de este medio, que recogía toda la información sobre el caso y los 
interpretaba para realizar una denuncia social. Pese a la cifra numérica, eldiario.es realizó un gran esfuerzo en la cobertura informativa de la tragedia de Tarajal, también desde su sección especializada en derechos humanos 'Desalambre'.

- En comparación con la cobertura en otros medios, el caso de las Tarjetas Black en El Confidencial puede resultar poco elevado. Cabe destacar este medio realiza informaciones en profundidad. Eldiario.es cubrió el caso de las Tarjetas Black con muchas píldoras informativas; El Confidencial lo hizo con publicaciones más extensas.

- Existe otro dato llamativo: La edición digital de El Mundo publicó un elevado número de artículos de opinión sobre la Lista Falciani, más que cualquier otro medio en términos comparativos.

Las exigencias informativas de la ciudadanía están cambiando; Antonio Delgado (2015) explica que "la ciudadanía está demandando un mayor nivel de transparencia, un mayor compromiso por parte de los medios, mejores recursos y una nueva forma de explicar las cosas" y, asegura, "los medios que se adapten a eso terminarán sobreviviendo y los que solamente se dediquen a copiar y pegar teletipos quizás no morirán, pero terminarán de una forma irrelevante".

\subsection{Corrupción, periodismo de datos y ley de transparencia}

Hasta finales del año pasado, España era el único país de la Unión Europea con más de un millón de habitantes que carecía de una Ley de Transparencia propia. Y si bien es cierto que la nueva legislatura 'Ley 19/2013, de 9 de diciembre, de Transparencia, acceso a la información pública y buen gobierno' ha permitido el acceso a ciertas informaciones, parece que ésta sigue siendo insuficiente. La ley entró en vigor el 10 de diciembre de 2014; su reglamento se hizo público el 10 de mayo de 2015. Por otra parte, se prevé que sea a finales de 2015, como tarde, cuando las Comunidades Autónomas y las entidades locales se incorporen a la ley.

El RTI Rating (Ranking de Derecho a la Información, por sus siglas en inglés) sitúa a España en el puesto 73 de 150 en nivel transparencia. El estudio ha sido elaborado por Access Info Europe (AIE) y el Centro para la Ley y la Democracia (CLD). Dicho estudio analiza la calidad de las legislaturas de transparencia y buen gobierno vigentes en los países europeos a través de determinados indicadores. Mar Cabra, una de las principales periodistas que reivindicó la necesidad de esta Ley cuando no existía, explica que los efectos de la Ley de Transparencia se irán notando de manera progresiva; de hecho, el número de peticiones desde que entró en vigor ha sido mucho menor de lo esperado ${ }^{5}$.

Delgado justifica el escaso número de solicitudes por la dificultad de uso del Portal de Transparencia: "No todo el mundo sabría utilizarlo, sólo los que tienen buen manejo de las nuevas tecnologías". Algunos organismos han solicitado modificaciones en el portal para hacerlo más accesible, entre ellos Access Info. En España la única manera de hacer peticiones de la Ley de Transparencia es a través del portal con DNI electrónico o con un certificado 
digital que requiere un lector y software adicional del que carece, según un informe realizado por Orange sobre acceso a la información, casi un 70\% de la población.

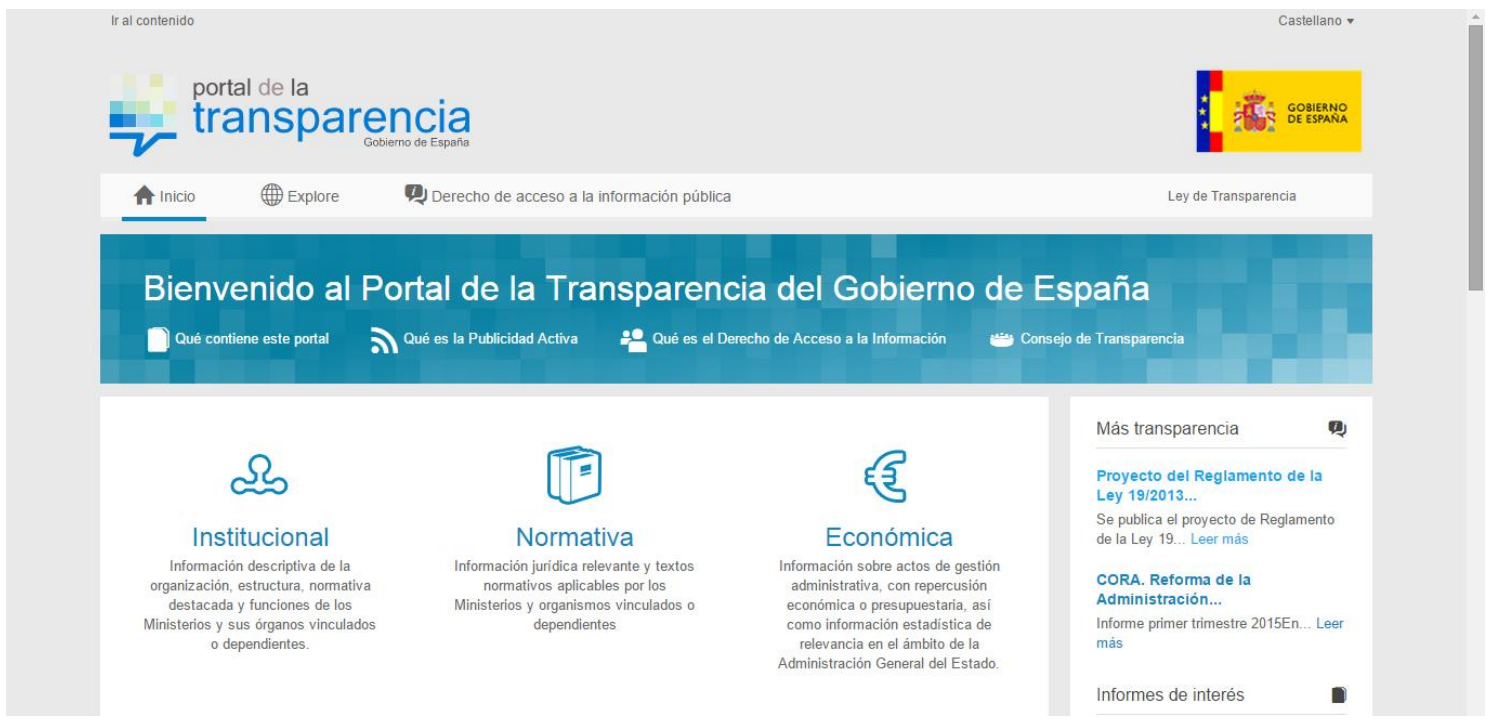

Ilustración 4 - Portada del Portal de la Transparencia del Gobierno de España | Fuente: transparencia.gob.es

En respuesta a una carta enviada por Access Info a la Defensora del Pueblo, ésta reconoció que el Portal de Transparencia puede tener un efecto disuasorio sobre el derecho de acceso a la información. Access Info denunciaba que el portal no explica cómo realizar solicitudes de información al margen del portal mismo; que los mecanismos para la utilización de éste resultan "sumamente complejos y excluyentes"; y que no debería exigirse la presentación de un DNI para solicitar información. Soledad Becerril, Defensora del Pueblo, otorgaba la razón a Access Info con respecto al primer y al segundo aspecto, pero matizaba que no aprecia irregularidades porque "la ley de transparencia establece claramente que se pueden enviar solicitudes por cualquier medio que permita tener constancia de la identidad del solicitante". En cuanto a la identificación del usuario, la respuesta de Becerril indicaba que las solicitudes anónimas "no tienen validez ni producen efectos jurídicos".

Los datos facilitados por la Administración a través de la Oficina de Transparencia y Acceso a la Información (OTAI), afirman que en sus seis primeros meses de funcionamiento, el Portal de Transparencia ha recibido más de dos mil solicitudes de acceso a la información. De estas solicitudes, casi un $85 \%$ han sido resueltas, un $6 \%$ están pendientes de revisar y menos de un $4 \%$ han sido archivadas.

Sin embargo, Access Info declara que la clasificación del estado de las solicitudes "les genera dudas" y que el sistema adoptado puede "llevar al engaño" y "dilatar el plazo de respuesta de forma arbitraria". El Confidencial, la Fundación Ciudadana Civio y Access Info Europe lanzaron 
en abril de 2015 una iniciativa ${ }^{6}$ para conocer los motivos esgrimidos por los organismos para denegar información pública.

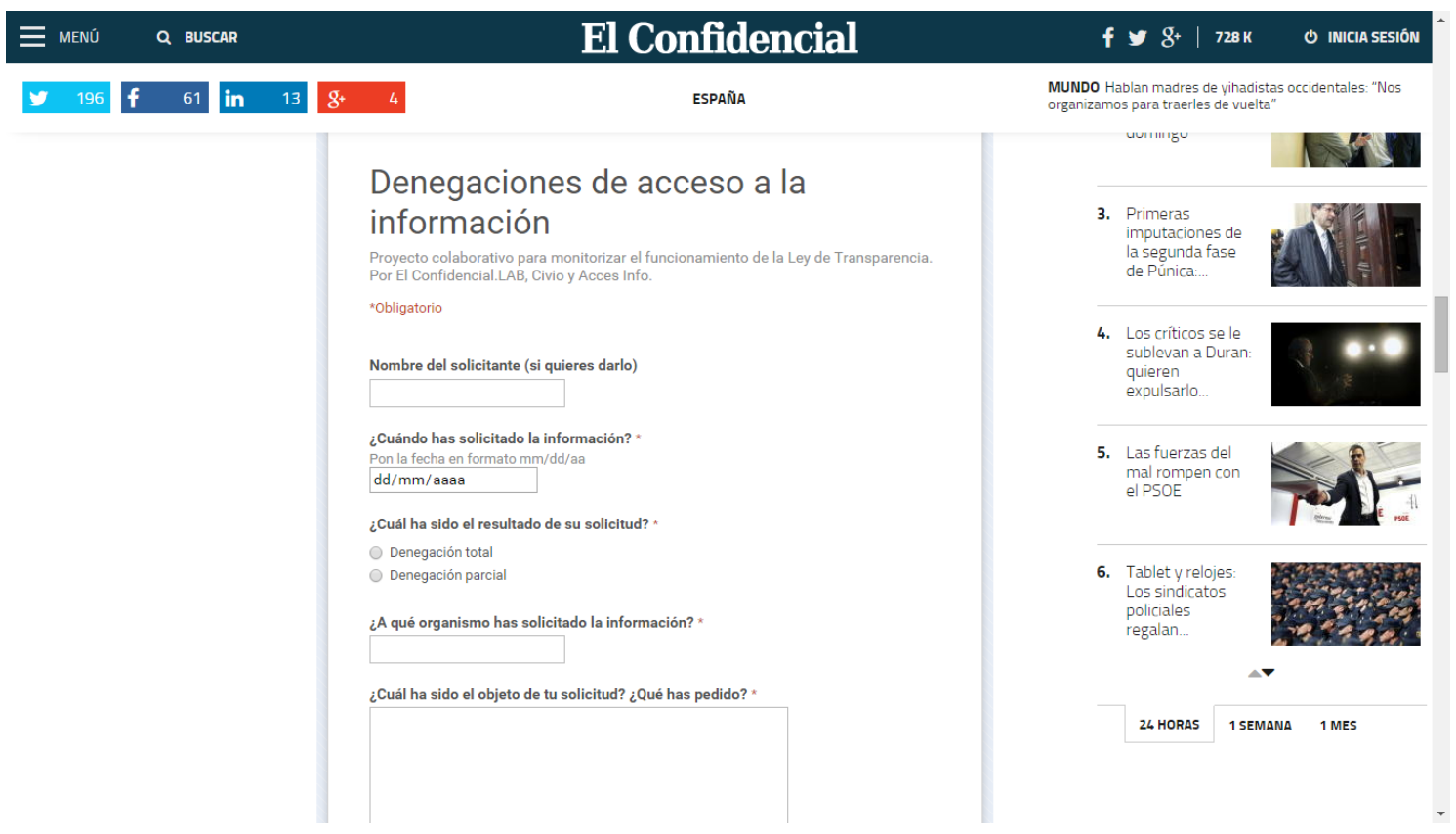

Ilustración 5 - Iniciativa colaborativa desde El Confidencial para conocer las causas de denegaciones de información / Fuente: El Confidencial

Mar Cabra asegura que el escaso uso del Portal no se debe al desinterés de la ciudadanía, sino al desconocimiento de la herramienta: "No se ha hecho publicidad del derecho de acceso a la información", defiende; "la mayoría de medios, tanto nativos digitales como tradicionales, hicieron pública la noticia de la entrada en vigor de la Ley, pero son muy pocas las informaciones que se han dado desde entonces”. En marzo de 2015, el Gobierno realizó una campaña publicitaria destinada a incentivar el uso del portal; sin embargo, apenas tuvieron impacto por el escaso presupuesto destinado a ella7.

No obstante, Mar Cabra considera que también es necesario que se produzca un cambio cultural en España: "Ahora tenemos una ciudadanía más activa, pero el ciudadano debe acostumbrarse a exigir más a las autoridades y a las administraciones". Antonio Delgado apoya esta afirmación: "Ya que tenemos una Ley de Transparencia, debemos utilizarla y crear esa cultura de hacer peticiones de información".

Desde la perspectiva del periodista, una de las grandes ventajas que presenta la Ley de Transparencia es que permite obtener exclusivas. La publicación de contenidos propios da prestigio a los medios de comunicación; cuando se solicita información a través del Portal, las peticiones son públicas pero la respuesta sólo la recibe el demandante. De esta forma, explica Antonio Delgado, se consigue material exclusivo con el que el periodista puede trabajar. La ley de Transparencia, explica Daniele Grasso, posibilita "tratar temas que se salen de la agenda mediática"; sin embargo, también considera que la información pública facilitada por las 
autoridades es insuficiente: "En El Confidencial hemos creado una aplicación que anuncia cuándo se suben nuevos contenidos al Portal de Transparencia; resulta curioso porque nos percatamos de lo mal que está gestionado y de la poca cantidad de contenidos que generan". El problema, señala Mar Cabra, es que esta información a menudo no se publica en formato reutilizable, lo cual hace complejo el análisis de datos. Precisamente el conocimiento del tratamiento de datos ha favorecido el objeto de estudio de este trabajo: el auge del periodismo de investigación política.

\section{4 Características del periodismo de investigación en los casos analizados}

\subsubsection{Tarjetas Black: colaboración ciudadana y periodismo de datos}

Antonio Delgado explica que el periodismo de datos es una disciplina que se engloba en el periodismo de investigación. En el caso de las Tarjetas Black, eldiarioes recibió una filtración de una fuente anónima derivada por la Comisión Ciudadana Anticorrupción del Partido X, liderada por Hervé Falciani, el informático del HSBC que filtró la mayor lista de evasores fiscales de la historia. La fuente anónima envió, el día 3 de diciembre de 2013, la correspondencia electrónica de Miguel Blesa a dicha Comisión a través del Buzón X, una plataforma de denuncia ciudadana, explicando que tenía "un volumen importante de información que dibujaba un cuadro claro de corrupción institucional en España".

Al recibir esta información, los colectivos $15 \mathrm{MPaRato}$, XNet y la Comisión Anticorrupción de Partido X se coordinaron para gestionar la información, la analizaron y la redirigieron a medios de comunicación. Ignacio Escolar, director de eldiario.es, resume la importancia de dicha filtración: "Los correos no sólo revelan errores ruinosos, enchufes y arbitrariedad. También hay material más que suficiente para una investigación penal”. De toda la información que contenían los correos de Blesa, sólo eldiario.es, La Sexta y 20 minutos centraron su atención en las tarjetas 'black'; en diciembre de 2013, eldiario.es publicaba una noticia titulada "Los consejeros de Caja Madrid tenían tarjetas de crédito 'en negro' de hasta 50.000 euros al año". Esta publicación hizo que el banco iniciara una investigación interna sobre las tarjetas 'black' de los directivos de Caja Madrid.

Pese a que el veredicto del despacho jurídico que analizó la investigación fue benévolo con los usuarios de las tarjetas ${ }^{8}$, Bankia remitió dicho informe, a fecha de 26 de junio de 2014, al FROB (dueña de las acciones del banco) que a su vez alertó, el 4 de julio, a la Fiscalía Anticorrupción. Fue entonces cuando se inició el proceso judicial a manos de Fernando Andreu, juez de la Audiencia Nacional, quien facilitó el 10 de octubre de 2014 el detalle de los pagos realizados con las tarjetas negras por parte de los 86 exdirectivos de Caja Madrid. 


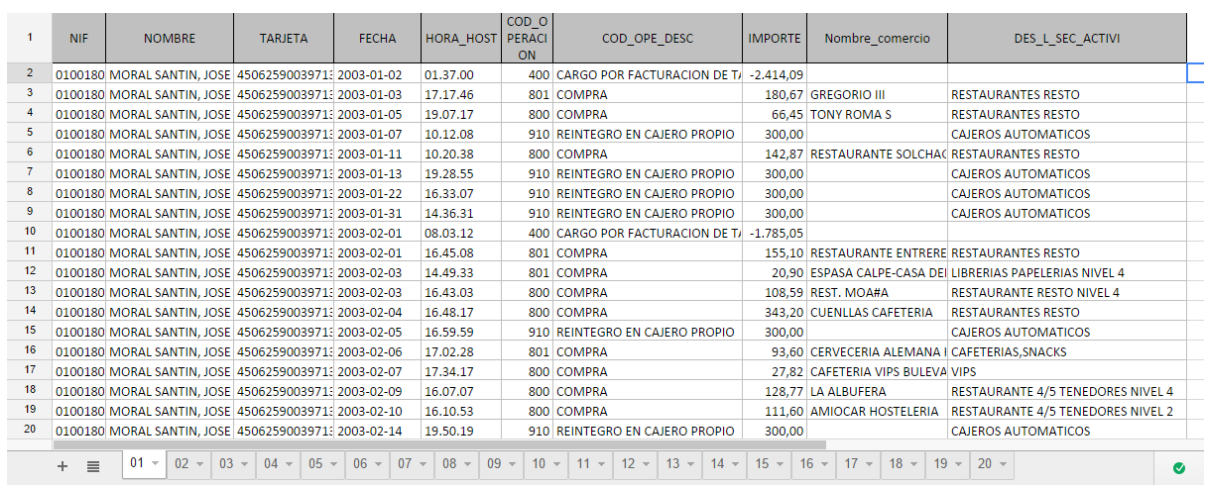

Ilustración 6 - Muestra de los registros de pago con las tarjetas 'black' / Fuente: Suscuentas

Antonio Delgado explica que dicha documentación se componía de siete ficheros en formato Excel, que fue remitido a varios medios de comunicación y profesionales de la información. El documento contenía todos los datos de los apuntes contables, es decir, de los usos de las tarjetas. Entre los campos de cada apunte contable se encontraban el NIF del usuario, su nombre, la tarjeta, la fecha y la hora de la operación, el importe y el comercio... En total eran 20 las hojas de cada uno de los siete documentos Excel y el número de registros ascendía a 84.000 .

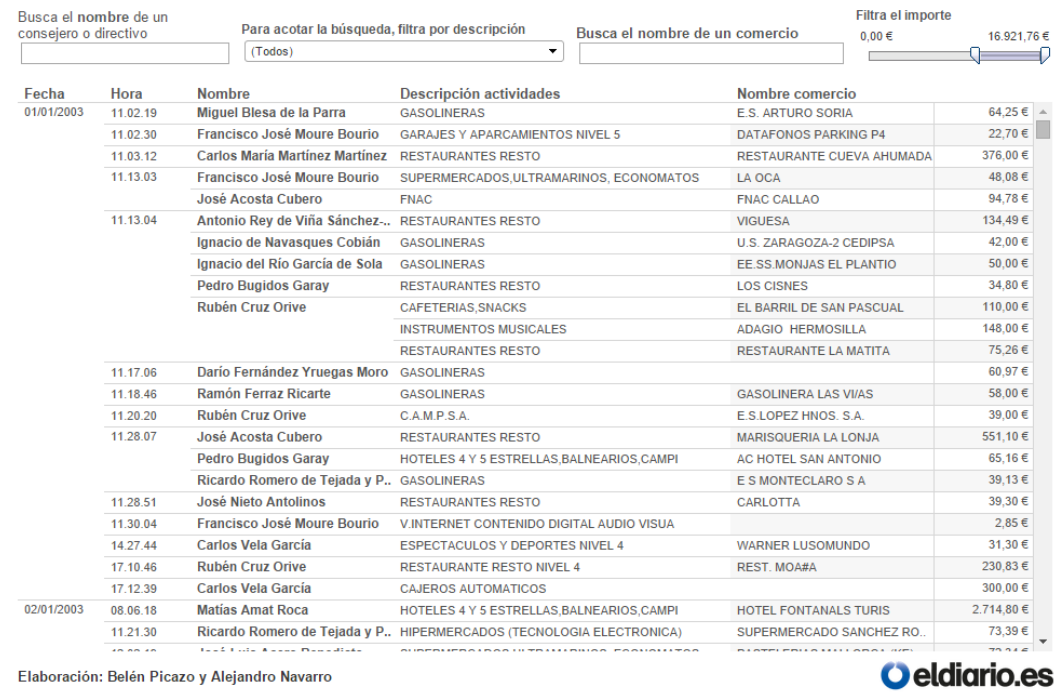

Ilustración 7 - Cargos en las tarjetas 'black' de Caja Madrid / Fuente: eldiario.es

Antonio Delgado insiste en la necesidad de que los medios de comunicación tengan su propia unidad de datos, para lo que se requiere profesionales formados en dicha disciplina. La implantación de unidades de datos en los medios de comunicación se está produciendo de manera progresiva: la de El Confidencial fue la primera en un medio español, pero en el último año se han sumado otros como La Sexta, El Mundo, La Vanguardia o El Español.

Pero el escándalo de los sobresueldos de los directivos de Caja Madrid no habría sido posible sin la colaboración de ciudadanos comprometidos. Simona Levi, miembro de XNet y del 
colectivo 15MPaRato, lo explicó en La Sexta Noticias: "Por mucho que haya partidos que intenten atribuirse el mérito, quien ha destapado esto [el caso de las tarjetas black] ha sido la ciudadanía organizada".

El impacto de la publicación del escándalo de las Tarjetas Black es innegable: un gran número de encuestados afirma que podría explicar con bastante detalle en qué consiste el Caso de las Tarjetas Black; sólo un 2,5\% asegura no conocerlo.

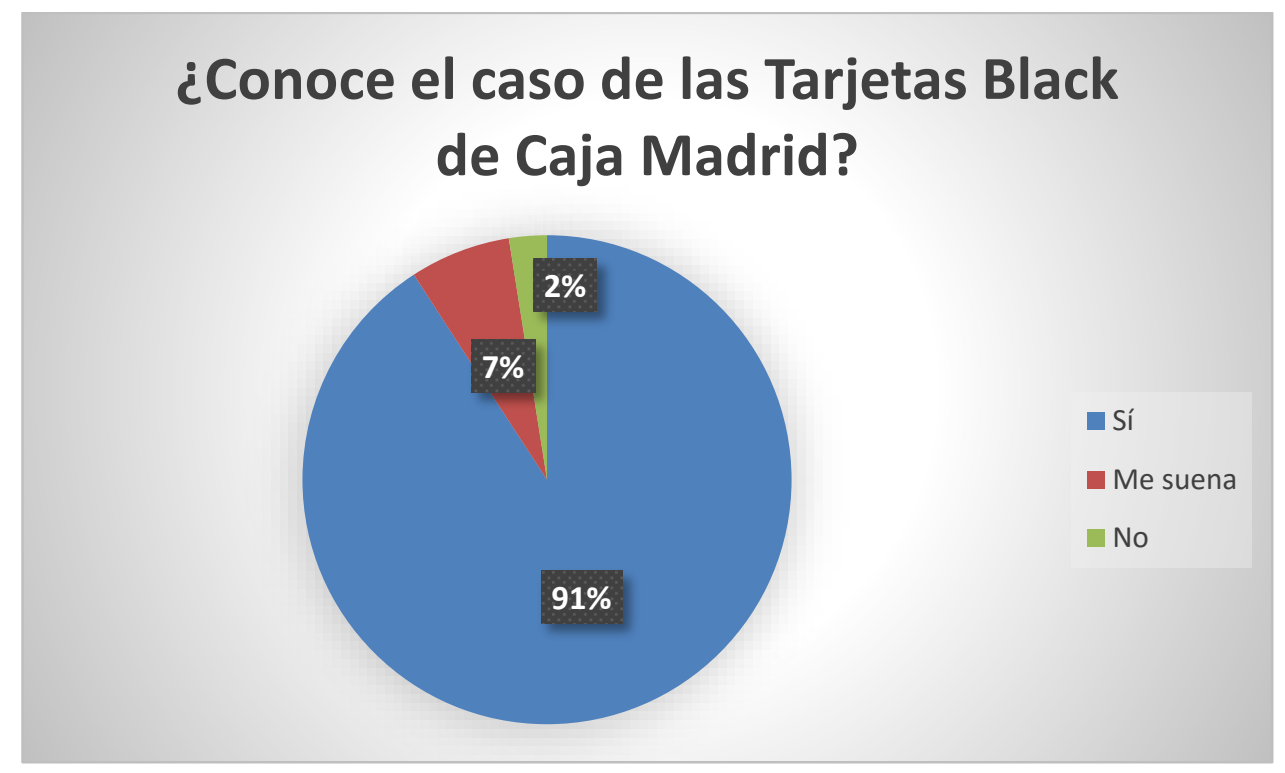

Ilustración 8 - Porcentaje de encuestados que conoce el caso de las Tarjetas Black / Fuente: Elaboración propia

\subsubsection{Lista Falciani: periodismo de investigación colaborativo}

Pese a que la publicación de los nombres de la Lista Falciani es reciente (en España, El Confidencial la publicó por vez primera el 9 de febrero de 2015), fue en 2008 cuando el entonces empleado de la filial suiza del banco HSBC, Hervé Faliani, filtró el documento que contenía el nombre de más de 100.000 clientes, provenientes de 200 países, que disponían de cuentas opacas. La Hacienda española recibió la información en 2010 y, gracias a ella, consiguió recaudar más de 260 millones de euros.

Sin embargo, no fue hasta principios de 2014 que el diario Le Monde recibió, por parte de fuentes del Gobierno francés, los 60.000 archivos de los que constaba la Lista Falciani; a partir de ese momento los medios pudieron iniciar la investigación. Ante el gran volumen de la filtración, el diario francés comprendió que sólo tenía capacidad para tratar periodísticamente las 3.000 cuentas relacionadas con Francia y que debía solicitar ayuda para que la lista pudiera 
ser analizada en su plenitud. De esta forma, recurrió al Consorcio Internacional de Periodistas de Investigación (ICIJ) para gestionar este trabajo. El ICIJ, explica Mar Cabra, llevaba trabajando con grandes filtraciones desde el año 2012; SwissLeaks (o Lista Falciani) fue la tercera, después de las investigaciones Offshore Leaks y LuxLeaks. En estos tres últimos años, relata Mar, el ICIJ ha refinado su metodología, con lo cual ahora "tenemos mucha más capacidad de desplegar plataformas de trabajo colaborativo entre periodistas y hacerlo de manera rápida, sencilla e integradora".

La redacción del Consorcio Internacional de Periodistas de Investigación (ICIJ) está formada sólo por 11 personas; Mar Cabra es la única periodista española que forma parte del equipo. Pero si bien la redacción de ICIJ es pequeña, la red de periodistas que colabora con el Consorcio es muy amplia. Así pues, el ICIJ facilita el trabajo colaborativo entre periodistas de todo el mundo. En el caso de SwissLeaks, se convocó una primera reunión en París en septiembre de 2014 a la que asistieron, explica Cabra, "unas treinta o cuarenta personas" y a partir de la cual "se sumaron otros periodistas o trabajadores de otras redacciones" que, finalmente, sumaron el total de los 170 periodistas que trabajaron en la investigación de la Lista Falciani.

El primer paso del ICIJ fue extraer información de los 60.000 archivos de Excel y reconstruir la base de datos, colocándolos posteriormente en una plataforma segura a la que los periodistas que trabajaban en el caso tuvieran acceso. Se crearon dos plataformas: una destinada a la búsqueda de documentos y un foro donde los periodistas se podían comunicar. El propio ICIJ elaboró una lista de nombres asociados a países, previo procesamiento de datos, para que cada periodista involucrado en la investigación pudiera consultar los nombres de las personas asociadas con cada país.

En el caso de España, el acuerdo de colaboración se estableció con El Confidencial, que puso a miembros de su plantilla a trabajar en el caso. Uno de ellos fue Daniele Grasso, periodista especializado en datos. Grasso encriptó su ordenador, de manera que la lista permaneciera oculta; más tarde, procedió al análisis de datos. Mar Cabra, por su parte, es jefa de la unidad de periodismo de datos, compuesta por cinco miembros de distintos países ${ }^{9}$ y que tiene su sede en Washington. Los integrantes de esta unidad analizaron los datos de la filtración y crearon las plataformas para que los reporteros del proyecto trabajaran con dichos datos de manera segura desde cualquier parte del mundo.

Posteriormente se procedió a la publicación de ésta de manera que fuera comprensible para el lector. El Confidencial difundió los nombres de personajes de relevancia pública que se encontraban en la Lista Falciani; Daniele Grasso explica que "se utilizó el nombre de personajes famosos para poner en entredicho que utilizaran la infraestructura del banco HSBC", pero que lo que les interesaba era "subrayar la conexión entre la cocaína, el tráfico de armas o el terrorismo con los paraísos fiscales". Grasso explica que lo destacable de la Lista Falciani no es que determinados personajes reconocidos tengan cuentas en paraísos fiscales, 
sino "que se utilicen, estén permitidos y sean legales; lo que estamos denunciando es, precisamente, que sea legal". Para conseguir mayor impacto, El Confidencial estableció una alianza con La Sexta: "Esto nos dio repercusión, ya que gran parte de la población se informa a través del medio televisivo".

El impacto del caso de la Lista Falciani fue menor que el anterior, según los resultados de nuestras encuestas. Un 80\% afirma conocer el caso de la Lista Falciani, pero sólo un 49\% de los encuestados asegura que sabría explicarlo de manera detallada:

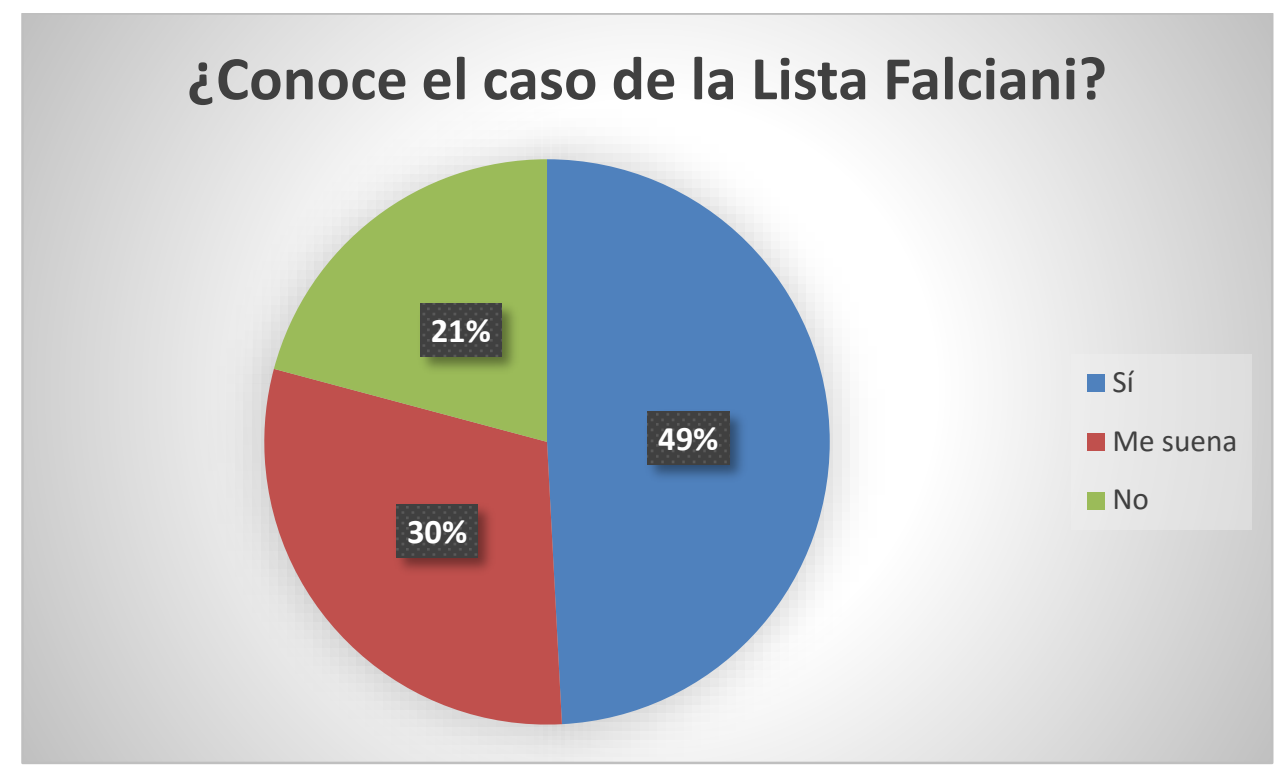

Ilustración 9 - Porcentaje de encuestados que conoce el caso de la Lista Falciani / Fuente: Elaboración propia

La publicación de los nombres que formaban parte de la Lista Falciani se realizó de manera progresiva. Grasso niega haber recibido presiones cuando estaba trabajando con los datos, pero narra que cuando éstos se hicieron públicos sí que recibieron críticas por no publicar la Lista Falciani completa. "No lo hicimos”, explica Grasso, "porque suponía sobreinformar al lector; además, muchos de los nombres no tienen interés público y la información contiene datos sensibles". Mar Cabra añade que "tener una cuenta en Suiza es legal, siempre que se declare a Hacienda, con lo cual publicar la lista completa es un error". Además, explica que en España la legislación no permite a la Agencia Tributaria publicar datos sobre los contribuyentes.

\subsection{Las Muertes de Ceuta: periodismo de denuncia a partir de fuentes oficiales}

Sin embargo, el periodismo de investigación, como se indicaba en el marco teórico, no tiene por qué iniciarse únicamente a partir de filtraciones. Marcos García Rey, periodista de datos, defiende que "el periodismo de iniciativa propia es el más valioso". La diferencia fundamental 
que presenta este tercer caso con respecto a los dos anteriores analizados es el punto de partida: la documentación oficial.

Es el caso de 'Las muertes de Ceuta', un especial multimedia elaborado por el nativo digital eldiario.es que pretende denunciar la realidad de la inmigración en España. Con el objetivo de esclarecer qué ocurrió el 6 de febrero de 2014, cuando un total de quince inmigrantes perdieron la vida intentando acceder a España, el especial recoge la documentación facilitada por las fuentes oficiales y la amplía con entrevistas a testigos.

A lo largo de un año eldiario.es, a través de la sección especializada en Derechos Humanos 'Desalambre', realizó una exhaustiva investigación contrastando la información oficial facilitada por el Gobierno con los testimonios de otras fuentes y revisando todas las imágenes disponibles de los momentos de las muertes. El objetivo del reportaje, además de servir como denuncia social, es arrojar luz sobre la responsabilidad de la Guardia Civil en la muerte de estas quince personas. En este sentido, las informaciones relativas a la tragedia de Tarajal son las menos conocidas por los encuestados: un 30\% de ellos asegura que no conoce en qué consiste el Caso Tarajal.

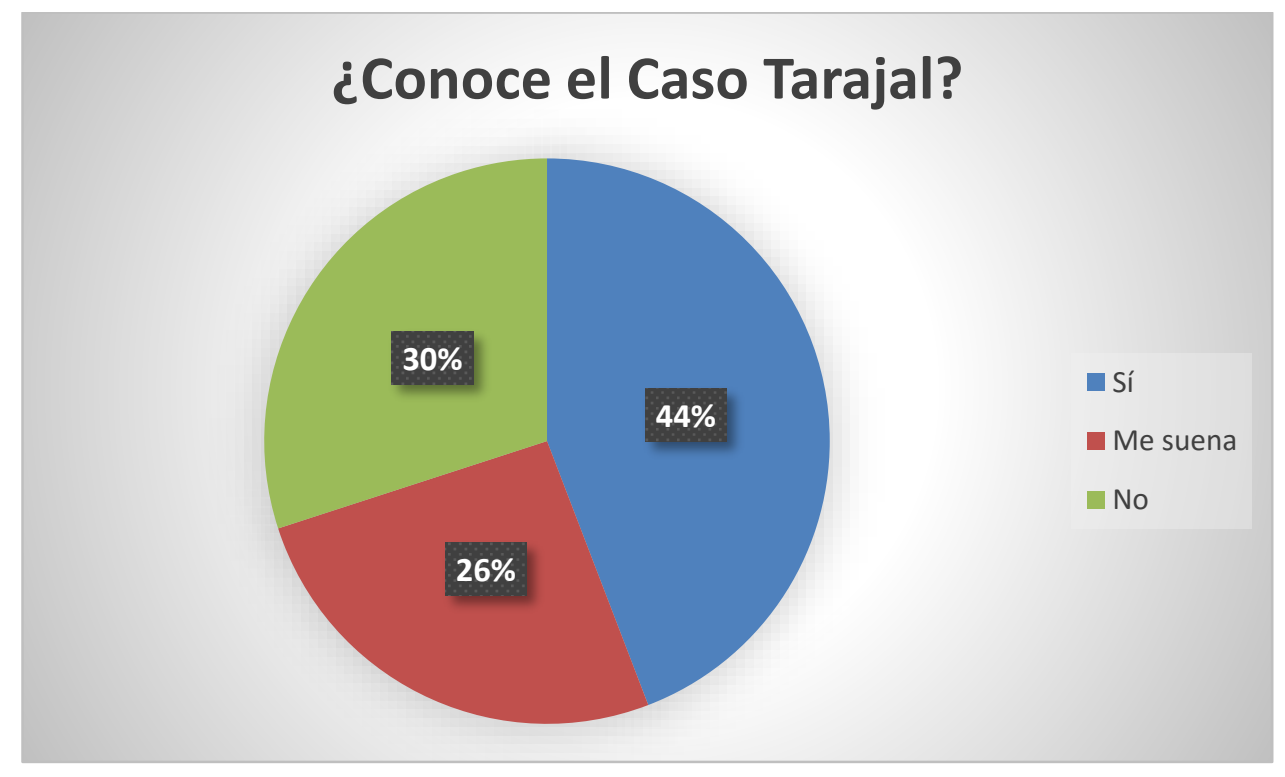

Ilustración 10 - Porcentaje de encuestados que asegura conocer el Caso Tarajal / Fuente: Elaboración propia

La metodología empleada por la redacción de eldiario.es consistió en analizar las ruedas de prensa y las declaraciones de las fuentes oficiales para demostrar que éstas se contradecían. Además, desde la redacción de eldiario.es se encargaban de realizar un exhaustivo seguimiento de los procesos judiciales referidos al caso. En total, fueron siete miembros de eldiario.es los que trabajaron para la elaboración de 'Las muertes de Ceuta'.

El especial de 'Las muertes de Ceuta' consta de varias partes:

- Un vídeo-documental de once minutos de duración en el que se reconstruyen los hechos acontecidos el 6 de febrero de 2014 a partir del material reunido en un año y extraído del Ministerio de Interior, emitido por cadenas de televisión y de radio ( $\mathrm{La}$ 
Sexta, Grupo Mediaset, Cadena Ser, esRadio) y otras fuentes documentales (Informes, sumarios o denuncias judiciales); así como entrevistas a los testigos directos.

- Además del vídeo, existen tres secciones en el especial multimedia alojado en 'lasmuertesdeceuta.eldiario.es' que emplean las nuevas tecnologías:

- "Los hechos": Narra de manera interactiva el minuto a minuto de la tragedia. Conforme el usuario hace scroll, puede encontrar vídeos o imágenes; además, el mapa situado a la izquierda expresa gráficamente lo que el texto narra.

○ "El contexto": En él se incluyen cuatro artículos redactados por diferentes miembros de eldiario.es.

○ "Las mentiras": De carácter interactivo, la sección está pensada para, tal como explica Alejandro Navarro, encargado de la parte audiovisual del proyecto, "poner a examen al usuario y hacer el trabajo más participativo".

- Cuaderno No 8 de eldiario.es "Fronteras y mentiras": Revista monográfica sobre inmigración, en cuyo número participan periodistas de prestigio tales como Olga Rodríguez, Javier Gallego, Pedro Águeda y Jesús Blasco.

- Seguimiento informativo del caso a través de la sección de eldiario.es 'Desalambre', especializada en derechos humanos.

El mérito del trabajo de investigación reside en que el único material gráfico del que disponían los miembros de eldiario.es era el que facilitaba el propio Ministerio del Interior: "Salvo los testimonios, con los que pretendimos aportar un punto de vista más humano, todo el material empleado es documentación oficial; los medios de comunicación no pueden acceder a la valla de Tarajal ${ }^{10}$, explica Alejandro Navarro, que insiste en la existencia de 'filtros' en las propias imágenes: "La persona que está en la cabina manejando la cámara graba lo que le interesa; hay partes de los brutos facilitados en los que la cámara mira al descampado".

\subsection{Cambios en el paradigma mediático que propician la publicación de casos de corrupción}

En las III Jornadas de Periodismo de Datos celebradas en Madrid de 2015, Daniele Grasso explicaba que la integración de una unidad de datos en los medios de comunicación favorecía un cambio en el paradigma mediático español. Grasso desglosaba tres factores vinculados con las unidades de datos:

- El tiempo: Daniele Grasso defiende que existe una gran diferencia en los resultados entre "el trabajo bien hecho y el trabajo rápidamente hecho". Mar Cabra explica que precisamente ésta es una de las grandes ventajas de trabajar en el ICIJ: "Disponer de tiempo suficiente para desarrollar la investigación resulta de gran ayuda". Al Shaw, periodista de datos de la plataforma ProPública, resume el motivo: "La limpieza y el análisis de datos requiere tiempo". Realizar estas investigaciones con tiempo implica que se dispone de más margen para contrastar las fuentes y evitar posibles errores. Al Shaw explica que en ProPública se realiza bulletproofing o 'periodismo a prueba de balas', esto es, un reanálisis de los datos. 
- Colaboración: Daniele Grasso explica que las grandes investigaciones que se han llevado a cabo los últimos años se han realizado mediante el trabajo colaborativo: "Ya no hay lobos solitarios, se trabaja en equipo". En este sentido, Mar Cabra explica que desde ICIJ y con el objetivo de promover la colaboración, cuando reciben una filtración se ponen en contacto con los medios de comunicación con los que han trabajado con anterioridad.

Grasso, por su parte, destaca la gran ventaja de este trabajo colaborativo: el impacto de las informaciones. "Se coordina una fecha de publicación y cada medio de comunicación publica la investigación en su idioma y en su plataforma; de esta manera, se logra un mayor impacto", explica.

- Nuevos perfiles profesionales en las redacciones: La inclusión de programadores en las redacciones de los medios es otro de los factores con los que Daniele Grasso justifica el cambio del paradigma mediático: "Hasta hace poco, los programadores y los periodistas trabajaban en dos plantas diferentes; la integración entre ambos perfiles profesionales se hace cada vez más necesaria".

\subsection{Impacto de las publicaciones de los casos analizados}

En el caso de las Tarjetas Black, la publicación de las informaciones derivadas del empleo de estas tarjetas se tradujo en un gran número de destituciones, dimisiones o cese de los titulares:

\begin{tabular}{|c|c|c|c|c|}
\hline Titular & Cargo & Partido & Gasto & Medidas \\
\hline Pablo Abejas Juárez & Director general de Economía de la Comunidad de Madrid y presidente de Avalmadrid & PP & 246.700 & Destituido \\
\hline María Carmen Cafranga Cavestany & Gerente de Tragsa & PP & 175.200 (devuelto) & Dimitido \\
\hline Angel Eugenio Gómez del Pulgar & Miembro de la Ejecutiva del Partido Socialista de Madrid (expulsado del partido) & PSOE & 149.700 & Dimitido \\
\hline Rodolfo Benito Valenciano & Respons. de la Secret. de Estudios de la Comisión Ejecut. Fed. de CC.OO & $\mathrm{CCOO}$ & 140.600 & Dimitido \\
\hline José María Arteta Vico & & PSOE & 139.000 & Expulsado del partido \\
\hline Gonzalo Martín Pascual & & UGT & 129.700 & Expulsado del PSOE \\
\hline Fernando Serrano Antón & Vocal del Tribunal Económico-Administrativo Municipal de Madrid & PP & 78.600 & Dimitido \\
\hline José María Buenaventura Zabala & Director de gabinete del secretario de Estado de Hacienda & PP & 63.000 & Dimitido \\
\hline Beltrán Gutiérrez Moliner & Gerente del PP de Madrid & PP & 58.000 (devolverá) & Dimitido \\
\hline María Enedina Alvárez Gayol & & PSOE & 47.200 & Expulsada \\
\hline Santiago Javier Sánchez Carlos & Vocal del distrito madrileño de Puente de Vallecas & PSOE & 47.200 & Dimitido \\
\hline Miguel Corsini Freese & Consejero de Mutua Madrileña & PP & 47.000 (ha devuelto) & Dimitido \\
\hline Juan Emilio Iranzo Martin & Consejero independiente de Red Electrica Corp. & PP & 46.800 & Dimitido \\
\hline José Ricardo Martínez Castro & Secretario general de UGT Madrid & UGT & 44.200 (Devolverá) & Dimitido \\
\hline Arturo Luis Fernández Alvarez & Vicepresidente de la CEOE & CEIM & 38.800 (Devuelto) & Dimitido \\
\hline Virgilio Zapatero Gómez & & PSOE & 36.000 (Devuelto 27.900 ) & Expulsado \\
\hline Ignacio Varela Diaz & & PSOE & 35.700 & Expulsado \\
\hline Joaquin Garcia Pontes & & PSOE & 21.100 & Expulsado \\
\hline Miguel Muñiz de las Cuevas & & PSOE & 20.800 & Expulsado \\
\hline José Nieto Antolinos & Vocal de la Junta municipal de Arganzuela & PP & 19.800 & Dimitido \\
\hline Jorge Rábago Juan Aracil & Miembro del Consejo de Telemadrid & PP & 8.300 & Dimitido \\
\hline Francisco Javier López Madrid & & CEIM & 34.800 (devuelto) & \\
\hline Juan Manuel Astorqui Portera & Vicepresidente de Burson-Marsteller en España & & 293.000 & Destituido \\
\hline Rafael Spottorno Díaz Caro & Consejero del Rey & & 235.900 (ha devuelto 17.000 ) & Dimitido \\
\hline Luis Gabarda Durán & Presidente de Inversis & & 139.700 & Dimitido \\
\hline María Elena Gil García & Consejera independiente de Jazztel & & 72.500 & Dimitido \\
\hline Rodrigo de Rato Figaredo & & & 99.000 (ha devuelto 54.800 ) & Dado de baja en el PP \\
\hline Ildefonso José Sánchez Barcoj & & & 575.100 (ha devuelto 90.900 ) & \\
\hline Matías Amat Roca & & & 431.000 (ha devuelto 42.000 ) & \\
\hline José Manuel Fernández Norniella & & & 185.500 (ha devuelto 9.700 ) & \\
\hline
\end{tabular}

Tabla 2 - Desglose de destituciones, expulsiones o dimisiones a raíz del caso de las Tarjetas Black / Fuente:

Elaboración propia 
Además de los cargos que se ha cobrado el escándalo de las tarjetas 'black', la investigación ha obligado a Hacienda a estudiar la posibilidad de que se produzcan prácticas similares en las compañías del Ibex 35 y en otras grandes empresas en España.

En cuanto a las consecuencias de la Lista Falciani, cabe recordar que tener una cuenta en suiza no es ilegal; lo que es ilegal es utilizar los paraísos fiscales para evadir impuestos. A raíz del presunto fraude fiscal en la filial suiza del HSBC, la fiscalía francesa demandó que un tribunal penal juzgase a dicha filial. Aparte de en Francia, el HSBC se enfrenta a investigaciones judiciales en Bélgica, Estados Unidos y Argentina. En el caso de Bélgica, la fiscalía de dicho país acusó al banco de asesorar a clientes del sector de los diamantes sobre cómo evadir impuestos.

Grasso destaca dos aspectos importantes derivados de la publicación de la Lista Falciani: destapar cuánto se ha extendido el sistema de fraude y colaborar en la protección de la figura del whisterblower. "No se trata de condenar a la persona que filtra la información, sino de protegerla cuando dicha filtración ha tenido efectos positivos para la sociedad y ha colaborado en la aprobación de una legislatura más justa”, explica Daniele Grasso. Falciani reconoció en una entrevista que deseaba cambiar de nombre, apellido y trabajo con el fin de "desaparecer de la sociedad". "Los periodistas deben proteger a sus fuentes, pero si el fin es bueno para la ciudadanía, el mismo Estado debería ayudar con esta protección”, argumenta el periodista.

Por último, a raíz de las investigaciones de las muertes de Ceuta y de la recogida de material audiovisual y testimonios de los protagonistas, un total de 16 guardias civiles fueron imputados por las muertes de Ceuta. Alejandro Navarro defiende que el proyecto tuvo repercusión: "Una semana después de la publicación del especial conmemorativo, se iniciaron procesos judiciales que apuntaban a los agentes de la Guardia Civil como sospechosos". Aunque en la actualidad el caso está archivado, se está contemplando la opción de reabrirlo. Además, el especial "Las muertes de Ceuta" de eldiario.es, tuvo gran impacto entre colegas de la profesión y ciudadanos, convirtiéndose en trending topic de Twitter durante dos días consecutivos.

El especial sobre las muertes de Ceuta fue presentado en varias provincias españolas y el 6 de mayo de 2015 el proyecto era presentado en Bruselas para denunciar ante el Parlamento Europeo la realidad de la inmigración y de los CIE (Centros de Internamiento de Extranjeros) en España.

Mar Cabra destaca la importancia del trabajo a posteriori: "El trabajo no acaba el día que publicamos la información; también es importante conocer el impacto de dichas informaciones a través de un seguimiento posterior". Para ello, en el ICIJ se lleva a cabo una tarea de rastreo: se investiga quién cita sus trabajo, quién los publica; incluso, se gestiona dicho impacto a través 
de las nuevas tecnologías: "Pedimos a algunos medios que utilicen un código identificativo mediante el cual nosotros conocemos quién lee estas informaciones, para calcular el impacto". El impacto real de un caso resulta evidente cuando provoca un cambio de la legislación vigente. Mar Cabra defiende que determinadas informaciones pueden producir cambios en la estructura y en la agenda política. Grasso añade la importancia de la colaboración entre periodistas para explicar este hecho: "Los cambios legislativos son un arma desde el punto de vista del periodista, que debe comprender que cuanto más largo sea el recorrido de una información, más impacto tendrá ésta. Ahí radica la importancia de la colaboración".

\section{Conclusiones}

De los resultados obtenidos podemos concluir que el auge del periodismo de investigación política no es casual: existen varios factores que favorecen la publicación de casos de corrupción política o abusos del poder. Estos factores están relacionados con el empleo de nuevos métodos y tecnologías en las redacciones y del trabajo colaborativo posibilitado por las nuevas formas de comunicación a través de Internet. Por lo tanto, resulta fundamentado afirmar que los medios de comunicación que disponen de los medios necesario para llevar a cabo estas investigaciones son los que más posibilidades tienen de destapar este tipo de escándalos.

Aunque la mayoría de los medios nativos digitales se han desarrollado utilizando estas herramientas, con lo cual la innovación forma parte de su configuración inicial, muchos medios tradicionales están apostando por introducir en sus redacciones aspectos de esta innovación periodística. De manera más detallada, podemos afirmar que

Conclusión 1. Se cumple la hipótesis 1: Los medios nativos digitales están recuperando la función del periodismo como cuarto poder o 'perro guardián de la Democracia'; esto es, los nuevos medios fiscalizan al poder politico.

En los resultados de este estudio, desglosábamos los tres factores establecidos por Daniele Grasso para justificar el cambio que está sufriendo el periodismo gracias a la integración de la unidad de datos en las redacciones de los diarios. Estos tres factores se pueden trasladar para justificar el auge del periodismo de investigación. El tiempo es un factor clave en el desarrollo de trabajos de investigación; y los nuevos perfiles profesionales y el trabajo en equipo resulta imprescindible para que el impacto de las informaciones sea más destacable.

El contexto político también favorece este cambio en el paradigma mediático. No obstante, a nivel institucional, el periodismo de investigación no siempre supone un cambio en el funcionamiento legislativo español. Daniele Grasso argumenta que sin una ley que regule el objeto de la investigación periodística, el trabajo no alcanza el impacto óptimo. Tal como indican los resultados de este estudio, los casos analizados sí que han llegado a los tribunales e 
incluso se han traducido en medidas políticas, pero éstas pueden resultar insuficientes. Sin embargo, es innegable que el periodismo de investigación ha permitido que los poderes políticos se sientan observados.

Sobre esto, Mar Cabra explica que más destacable que el hecho de que el periodismo esté recuperando su labor de vigilancia, es que esta labor de vigilancia sea global: "Hoy en día las informaciones cruzan las fronteras con mucha facilidad; si los temas que investigamos, tales como la corrupción o el crimen organizado se expanden, los periodistas también debemos unir fuerzas para seguir este rastro".

El estudio demuestra que el impacto real de estas informaciones se logra cuando los medios de comunicación más consumidos se hacen eco de las noticias. Esto hace evidente la necesidad de que el periodismo recupere su función de servicio público y lo haga en todos los soportes. Cabe destacar que sólo un 4\% de los encuestados sabía que El Confidencial fue el medio que publicó en exclusiva las informaciones relativas a la Lista Falciani; y sólo un 5\% de los encuestados sabe que fue eldiario.es quien mencionó por vez primera la existencia de "tarjetas black a efectos fiscales".

Del estudio podemos concluir que también se cumple la hipótesis 2: En España, el periodismo de investigación está ganando prestigio través del análisis de datos y del empleo de nuevas tecnologias y nuevas narrativas.

Los medios de comunicación españoles están implantando, de manera progresiva, unidades de datos en sus redacciones. Si bien El Confidencial fue pionero, cada vez son más los medios que se suman a la iniciativa: ya lo han hecho La Sexta y El Mundo, entre otros. Guillermo SánchezHerrero, periodista de datos de El Mundo, explica que en el caso de los medios tradicionales resulta complicado "mover la maquinaria de un modelo que lleva años en funcionamiento". No obstante, Adolfo Antón Bravo, periodista especializado en datos, reitera la necesidad de "apostar por el periodismo de calidad, abierto, participativo, y que logre una transformación; y eso sólo se hace con apertura de datos, con transparencia, y con nuevas tecnologías que faciliten este trabajo".

Sin embargo, cabe añadir a estos dos factores un tercero que no estaba contemplado en las hipótesis propuestas al inicio del estudio: la colaboración. Ya sea entre profesionales de distintos ámbitos (en una misma redacción) o entre numerosos medios de comunicación (investigaciones nacionales o internacionales), el rigor de las investigaciones se amplía cuanto más profesionales trabajan en ellas, y su impacto es mayor cuando la difusión se realiza desde diferentes medios.

El análisis de las informaciones publicadas en los medios de comunicación demuestra que se cumple la hipótesis 3: La independencia económica y politica de los medios nativos digitales favorece la 
publicación de informaciones contrarias a los intereses políticos y que, con matices, también se cumple la hipótesis 4: Los medios tradicionales están limitados en la publicación de determinadas informaciones obtenidas por los nativos digitales, pese a que éstas sean de gran interés para la ciudadanía. Según los resultados de otros estudios analizados en esta investigación, la cobertura de los casos de corrupción política resulta insuficiente, pero se puede percibir que determinados medios tradicionales que están realizando un esfuerzo por difundir determinadas informaciones incómodas para el poder político. No obstante, resulta evidente que las presiones políticas y empresariales que reciben los medios de comunicación tradicionales, que necesitan cubrir sus gastos, impiden que las informaciones referidas a determinadas empresas o instituciones sean publicadas con total libertad. La desconfianza en los medios tradicionales se hace evidente: la del periodista es la segunda profesión peor valorada del mundo en 2014.

Por el contrario, favorece esta tarea de vigilancia de los poderes públicos la creación de plataformas que velan por los intereses de los ciudadanos, como Civio, Access Info, Tuderechoasaber; la de agencias de noticias independientes y sin ánimo de lucro, como ProPublica; y los medios de comunicación que mantienen su independencia económica, como los estudiados El Confidencial o eldiario.es.

Se cumple la hipótesis H5: La participación ciudadana y las herramientas de filtración de informaciones van en aumento y posibilitan que salgan a la luz casos de corrupción politica.

Con el objetivo de favorecer la fiscalización del poder político, algunos medios de comunicación han propulsado la creación de plataformas de filtraciones ciudadanas como Filtral.la. Algunos escándalos de corrupción política se inician a raíz de una filtración: resulta importante, por tanto, respetar el anonimato de la fuente que pretende denunciar la mala gestión de los fondos públicos o los abusos del poder que perjudican a los ciudadanos. La creación de buzones para filtraciones resulta de gran utilidad para el periodismo de investigación.

No obstante, el trabajo de investigación apunta a que la participación ciudadana todavía no es suficiente: de los resultados obtenidos se puede concluir que no se cumple la hipótesis $6 \mathrm{La}$ nueva Ley de Transparencia y los contenidos a los que se puede acceder a través de ésta están siendo aprovechados por los profesionales de la información para denunciar casos de corrupción o abusos del poder.

Según nuestro análisis del contenido, existen evidencias significativas de que el Portal de Transparencia no ha recibido un gran número de peticiones de información por parte de los ciudadanos. La exigencia ciudadana resulta indispensable; tanto la población como los profesionales de la información deben hacer uso de las herramientas puestas a su alcance para exigir a las Administraciones un mayor nivel de transparencia: ésta es la primera de una serie de propuestas pensadas para mejorar el periodismo de investigación política en España. La segunda propuesta consiste en adaptar los planes de estudio de universidades para formar a los futuros profesionales en disciplinas, herramientas y metodologías que respondan a las nuevas necesidades informativas de los ciudadanos. 
Además, consideramos necesario que las fundaciones españolas fomenten las ayudas a periodistas con el fin de generar contenidos, y que éstas permitan al profesional trabajar con total libertad en sus investigaciones. Se hace evidente la ventaja que supondría para el prestigio del periodismo español una mayor convocatoria de grants o becas para destinadas a los trabajos de investigación de los periodistas. Tal como afirma Mar Cabra, en España todavía son escasos los concursos abiertos en los que el periodista puede presentar propuestas; y cuando son aceptadas, asegura la periodista de datos, según la fundación que emita esta ayuda puede resultar especialmente difícil mantener la independencia.

Nuestra cuarta y última propuesta, y que resume la esencia de las tres anteriores, es fomentar la creación de nuevos medios de comunicación e impulsar la propuesta de opciones innovadoras en los ya existentes. Estos medios han de adaptarse a las nuevas necesidades informativas del lector; las redacciones de los medios de comunicación deben perder el miedo a innovar. Antonio Delgado explica que la innovación en periodismo se está produciendo en la periferia, en los medios nativos digitales, como eldiario.es o El Confidencial. Sin embargo, cada vez son más los medios tradicionales que introducen cambios en sus redacciones para adaptarse a las demandas del lector.

El desarrollo de las nuevas tecnologías y la adaptación de los medios de comunicación resulta un objeto de estudio fundamental para comprender la evolución del paradigma mediático. Por ello, como futuras líneas de investigación, bien para un Trabajo de Fin de Máster o una Tesis Doctoral, se propone la continuación de este estudio a través del análisis de los cambios en las redacciones de los medios y de los nuevos perfiles profesionales, así como del desarrollo del periodismo de datos y la posible evolución de la transparencia en España, a partir del análisis y la interpretación de los datos facilitados por fuentes oficiales.

El proceso de cambio que está sufriendo el periodismo está estrechamente vinculado a los factores estudiados con anterioridad. Las nuevas herramientas, técnicas y metodologías; así como la apuesta por nuevos perfiles profesionales y el mantenimiento de la independencia de los poderes políticos, pueden contribuir a un periodismo más riguroso y, por ende, de mayor calidad. 


\section{Bibliografía}

20minutos.es (2014): “Hacienda investigará si las empresas del Ibex usan 'tarjetas B', además de Bankia", en 20minutos.es, España, octubre: http://www.20minutos.es/noticia/2255914/0/hacienda-investigar/uso-tarjetas-b-opacasfantasma/grandes-empresas-bankia/ [Consultado en enero de 2015]

ACCESS INFO (2015). "La Coalición Pro Acceso critica las graves carencias con las que entra en vigor la ley de transparencia". En Access-info.org, España, diciembre: http://www.accessinfo.org/es/esp-es/13630 [Consultado en marzo de 2015]

--- (2015). "El Defensor del Pueblo reconoce que el Portal de Transparencia puede tener un efecto disuasorio sobre el derecho de acceso a la información”, Access Info, abril de 2015, España. Extraído de: http://www.access-info.org/es/esp-es/15451[Consultado en junio de 2015]

ACEPRENSA (2015)."¿Periodismo de investigación o de filtración?”, en UnirRevista, mayo, España. Extraído de: http://blogs.unir.net/3931-periodismo-de-investigacion-o-de-filtracion [Consultado en junio de 2015]

ÁVILA, Ana María (2008): Periodismo de datos. Historia y situación actual, en VV AA, Manual de Periodismo de Datos Ibreoamericano. Chile: Fundación Poderomedia.

BARBER, Benjamin (2004): Democracia fuerte. Política participativa para una nueva época. Madrid: Alzumara

BOYNTON, Robert (2015): El nuevo Nuevo Periodismo. Conversaciones sobre el oficio con los mejores escritores estadounidenses de no ficción. Barcelona: Periodismo activo 6.

BURGH, Hugo (2008): Investigate Journalism. Context and Practice. Nueva York: Routledge. Pág. 140

CANEL, María José (2006): Comunicación política. Una guía para su estudio y práctica. Madrid: Tecnos. Pág. 17

CASTAÑO SENCIANES, Albert (2014): Periodismo de filtración. El caso Prism. Trabajo de Fin de Máster UAB. Pág. 12. Extraído de: http://www.recercat.cat/bitstream/handle/2072/240256/Trabajo $\% 20$ final $\% 20 \mathrm{de} \% 20 \mathrm{~m} \% \mathrm{C}$ 3\%A1ster.pdf? sequence $=1$ [Consultado en febrero de 2015] 
CASERO-RIPOLLÉS, Andreu (2012): Periodismo político en España: concepciones, tensiones y elecciones. En CAL, Cuadernos Artesanos de Latina, núm. 33, VV AA (Editor: Andreu CaseroRipollés). Tenerife: Sociedad Latina de Comunicación Social.

CIS. "Tres problemas principales que existen actualmente en España". Centro de Investigaciones Sociológicas (CIS). Extraído de: http://www.cis.es/opencms/Archivos/Indicadores/documentos html/TresProblemas.html_[Consultado en mayo de 2015]

DADER GARCÍA, José Luis (1987): Opinión pública y periodismo: claves para una reflexión crítica. Pamplona: Facultad de Ciencias de la Información.

--- (1992). El desarrollo teórico-práctico del periodismo sociológico: opinión pública y periodismo de precisión. Elperiodista en el espacio público. Barcelona: Bosch.

--- (2012): Periodismo politico y politica del periodismo: imaginando un futuro digno y sostenible. En Berrocal Gonzalo, S. y Campos Domínguez, E. (eds): La investigación en periodismo político en el entorno de los nuevos medios. Madrid: SEP.

--- y GÓMEZ FERNÁNDEZ, Pedro (1993): Periodismo de precisión: Una nueva metodología para transformar el periodismo. Anàlisi: Quaderns de comunicació, número 15, pp. 99-116

DEMERS, David Pearce y NICHOLS, Suzanne (1987). Precision Journalism. A Practical Guide. Nueva York: Sage Publications.

DÍA GÜELL, Luis (2003). Periodismo y periodistas de investigación en España, 1975-2000: Contribución al cambio político, jurídico, económico y social. Madrid: Tesis Doctoral, pp. 387- 426.

DOZ, Javier (2014). "Crisis, desafección ciudadana y refundación de la Unión Europea”, en Nuevatribuna.es, mayo, España. Extraído de: http://www.nuevatribuna.es/articulo/culturashispanicas/crisis-desafeccion-ciudadana-y-refundacion-unioneuropea/20140522160836103709.html [Consultado en marzo de 2015]

ELORDI, Carlos (2014). "Y, ¿qué pasó con la corrupción?” en Eldiario.es, mayo, España. Extraído de: http://www.eldiario.es/zonacritica/paso-corrupcion 6 256234379.html [Consultado en mayo de 2015]

ESCOLAR, Ignacio (2014): "Retrato del poder en España (con Aznar de fondo)". En Cuadernos de eldiario.es, "Retrato del poder", № 7, invierno de 2014. Kindle.

FLORES VIVAR, Jesús y SALINAS AGUILAR, Cecilia (2013): El periodismo de datos como especialización de las organizaciones de noticias en Internet. Correspondencia \& Análisis, No 3 pp. 1532. 
GIL, Andrés (2014): "Cómplices 'por un plato de consejo". En Cuadernos de eldiario.es, "Retrato del poder", No 7, invierno de 2014. Kindle.

LÓPEZ GARCÍA, Guillermo (2011): Politica binaria y spam electoral. Elecciones Generales 2008: nuevas herramientas, viejas actitudes. Valencia: Tirant lo blanc.

GALINDO, Jorge (2013): “Corrupción, castigo electoral y papel de independencia de los medios", en Politikon el 3 de febrero de 2013, España. Extraído de: http://politikon.es/2013/02/03/corrupcion-castigo-electoral-y-el-papel-de-la-

independencia-de-los-medios [Consultado en marzo de 2015]

GARCÍA ARÁN, Mercedes (2014). "Corruptos y corruptores, controles y sanciones". Cuadernos de eldiario.es, N7, "La caja B de la Democracia". Otoño de 2014. Kindle.

GOMIS, Lorenzo (1991): Teoría del periodismo. Cómo se forma el presente. Barcelona: Paidos. Pág. 179.

GONZÁLEZ FERRER, Amparo (2015): "El juego de la confusión”. En Cuadernos de eldiario.es, No 8, "Fronteras y mentiras", invierno 2015, pp. 74-75.

HABERMAS, Jürgen (1981). Historia y Crítica de la Opinión Pública. Gustavo Gili, Serie MassMedia, 2da. Edición. Barcelona, 1981. Págs. 37-39.

HALLIN, Daniel C. y MANCINI, Paolo (2008). Sistemas mediáticos comparados. Tres modelos de relación entre los medios de comunicación y la politica. Bacelona: Editorial Hacer. Pág. 167

PELLICER, Miquel (2014). "Mar Cabra: En España se confunden Periodismo de investigación y periodismo de filtración". En miquelpellicer.info, febrero de 2014, España. Extraído de: http://miquelpellicer.info/2014/02/mar-cabra-se-confunde-periodismo-deinvestigacion-y-periodismo-de-filtracion/ [Consultado en enero de 2015]

PÉREZ HERRERO, Pilar (2011): “El sistema mediático-político en España”. En López García, G. (ed.): Política binaria y spam electoral. Elecciones Generales 2008: nuevas herramientas, viejas actitudes. Valencia: Tirant lo blanc.

M. ALBERTOS, José Luis (1994): "La tesis del perro-guardián: revisión de una teoría clásica". En Estudios sobre el mensaje periodístico, Nº1, pp. 14-22.

MARTÍNEZ NICOLÁS, Manuel (2011): "De la democracia mediática a la democracia digital". Pont-e-virgula, no 9. Págs. 14-34. 
MEYER, Philip (1973): Precision Journalism. A Reporter's Introduction to Social Science Methods. Bloomington: Indiana University Press. Pág. 249.

MONTERO, José Ramón y TORCAL, Mariano. "No es el descontento, es la desafección". El País, junio de 2013, España. Extraído de: http://elpais.com/elpais/2013/06/11/opinion/1370978768 828729.html [Consultado en enero de 2015]

MOSCO, Vincent (2009): The Political Economy of Communication. Londres: SAGe. Pág. 163

MUÑOZ, Alejandro (1990). Opinión Pública y comunicación política. Madrid: Eudema Universidad.

NORRIS. P (2000): A virtuous circle: Political communication in post-industrial societies. Cambridge: Cambridge University Press.

ORANGE. "Informe anual sobre el desarrollo de la información en España 2014”. Pág. 140. Extraído de: http://www.proyectosfundacionorange.es/docs/eE2014/Informe eE2014.pdf [Consultado en junio de 2015]

PÉREZ DURÁN, Ixchel (2013): "Qué se puede esperar de la transparencia”, en politikon.com, 19 de junio de 2013, España. Extraído de: http://politikon.es/2013/06/19/que-se-puede-esperar-de-la-transparencia [Consultado en abril de 2015]

SIMÓN, Pablo. "Nuevos partidos a hombros de grandes medios". En Politikon, 13 de febrero de 2014, España. Extraído de: http://politikon.es/2014/02/13/nuevos-partidos-a-hombrosde-grandes-medios/

SÁNCHEZ, Juan Luis (2015): "Las mentiras que nos contaron la verdad". En Cuadernos de eldiario.es, No 8, "Fronteras y mentiras", invierno 2015, pp. 6-13.

SOSTOA, Osmar (1999): Periodismo, opinión pública y ciudadanía. IX Encuentro de El corredor de las ideas. Extraído de: http://www.corredordelasideas.org/docs/ix.../4ta mesa osmar sostoa.pdf [Consultado en enero de 2015]

TORCAL, Mariano. "Informe de resultados de la Quinta Edición de la Encuesta Social Europea (2010-2011)". European City Survey. Extraído de: http://www.upf.edu/ess/_pdf/5a-ola/Datos/ResultadosQuintaEdicion_FINAL.pdf 
URQUIZU, Ignacio (2014). "Corrupción, ciudadanía y democracia". En Cuadernos eldiario.es, No7, "La caja B de la democracia". Octubre de 2014. Kindle.

VELASCO, Pilar (2014). "Suiza, el agujero negro de la democracia". En Cuadernos eldiario.es, No7, "La caja B de la democracia". Octubre de 2014. Kindle. 


\section{Notas}

${ }^{1}$ Esta teoría tiene sus orígenes en el siglo XVII, y fue propulsada por teóricos como Stuart Mill, Smith Meyer o Roberts. La tarea del periodismo como perro guardián del sistema democrático está estrechamente vinculada con el periodismo de investigación, ya que la prensa "asume (...) la defensa de transparencia democrática, al sacar a la luz los casos a menudo ocultos e invisibles por su propia naturaleza” (Maria Ansón, 2009)

2 El Partido X es una formación política creada en 2012 y estrechamente vinculada al movimiento ciudadano $15 \mathrm{M}$. La particularidad de este partido es que funciona de manera virtual. Se autodefine como una "red ciudadana organizada para acabar con la corrupción y conseguir una verdadera democracia”. Aunque la formación apoyada por el informático Hervé Falciani se presentó a las elecciones europeas de 2014 y consiguió más de cien mil votos, renunció presentarse a las elecciones municipales y autonómicas de 2015.

${ }^{3}$ El Art. 1 de la Constitución Española (1978), recogido en el Título Preliminar del texto, enuncia que "España se constituye en un Estado social y democrático de Derecho que propugna como valores superiores de su ordenamiento jurídico la libertad, la justicia, la igualdad y el pluralismo político”. En cuanto al derecho a la información, éste viene recogido en el Artículo 20, Capítulo II, Sección primera: 'De los derechos fundamentales y de las libertades públicas".

${ }^{4}$ Un ejemplo de ello es el caso de eldiario.es. Este medio de comunicación, además de su portal digital, publica periódicamente números de su colección de 'Cuadernos', algunos de ellos utilizado como material bibliográfico en este estudio. En los 'Cuadernos' participan miembros de la redacción y profesionales relacionados con la materia tratada en cada monográfico. Además, colabora en el programa de radio online Carne Cruda, dirigido por Javier Gallego.

${ }^{5}$ De las 25.000 peticiones de información que esperaba recibir la Agencia Española de Protección de Datos, sólo se realizaron un total de 1.800 solicitudes de información (período comprendido entre la entrada en vigor de la Ley, en diciembre de 2014, hasta abril del 2015).

${ }^{6}$ La iniciativa colaborativa consiste en que los ciudadanos o periodistas que hayan recibido una respuesta negativa rellenen un formulario con los motivos esgrimidos por los ministerios para denegar dicha información: http://www.elconfidencial.com/espana/2015-0421/transparencia-administraciones-publicas-informe-tuderechoasaber_763265/

${ }^{7}$ Se invirtió un total de 500.000 euros en la campaña, en la que se pusieron anuncios en medios tradicionales e Internet. Un portavoz de la presidencia reconoció que debía haberse invertido una cantidad mayor de dinero y que aunque se notó un incremento en visitas y solicitudes, las cifras seguían sin ser destacables. Fuente: http://politica.elpais.com/politica/2015/06/07/actualidad/1433702508 402702.html

${ }^{8}$ El veredicto sobre la investigación interna del uso de las tarjetas se encargó al despacho Herbert Smith Freehills, que no apreció indicios de delitos; no obstante, Bankia decidió reclamar la devolución de fondos retirados a un grupo de directivos y envió éste y otros informes al Frob.

${ }^{9}$ La unidad de datos del Consorcio Internacional de Periodistas de Investigación (ICIJ) está compuesta por cinco personas; Mar Cabra trabaja ocupa el cargo de editora y coordina a cuatro 
personas: una periodista de datos que trabaja desde Washington y un analista de datos en Costa Rica; una editora de investigaciones en Venezuela y un desarrollador de aplicaciones web en Costa Rica. La sede central de la unidad de datos del ICIJ se encuentra en Washington D.C. La unidad de datos e investigación del ICIJ se compone de la mitad del personal que conforma el ICIJ.

10 Alejandro Navarro explica que la valla de Tarajal, que separa Ceuta de Marruecos, "se considera perímetro fronterizo y posee seguridad especial" con lo cual el acceso con cámaras está denegado. De esta forma, para el especial 'Las muertes de Ceuta', el equipo de eldiario.es tuvo que trabajar con el material proporcionado por las fuentes oficiales. 


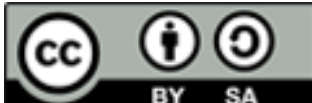

Licencia Creative Commons

Miguel Hernández Communication Journal

mhcj.es

Forma de citar este artículo en las bibliografías

Lis Gaibar García (2015): "Periodismo de investigación política en nuevos medios: Lista Falciani, Tarjetas Black y Caso Tarajal” en Miguel Hernández Communication Journal, nº, páginas 91 a 128. Universidad Miguel Hernández, UMH (Elche-Alicante). Recuperado el _ de de $20 \ldots$ de: @ink del artículo en mhjournal.org] 